\title{
Article \\ A FDEM Parametric Investigation on the Impact Fracture of Monolithic Glass
}

\author{
Xiangxiang Chen ${ }^{1}$, Xudong Chen ${ }^{1, *(\mathbb{D}}$, Andrew Chan ${ }^{2}{ }^{(\mathbb{D}}$, Yingyao Cheng ${ }^{2}$ and Hongfan Wang ${ }^{3}(\mathbb{D}$ \\ 1 School of Civil Engineering, Suzhou University of Science and Technology, Suzhou 215011, China; \\ chenxx160619@163.com \\ 2 School of Engineering, University of Tasmania, Hobart 7001, Australia; andrew.chan@utas.edu.au (A.C.); \\ yingyao.cheng@utas.edu.au (Y.C.) \\ 3 Department of Civil Engineering, The City College of New York, New York, NY 10031, USA; \\ hongfanwang@gmail.com \\ * Correspondence: chenxd@usts.edu.cn
}

Citation: Chen, X.; Chen, X.; Chan,

A.; Cheng, Y.; Wang, H. A FDEM

Parametric Investigation on the Impact Fracture of Monolithic Glass. Buildings 2022, 12, 271. https:// doi.org/10.3390/buildings12030271

Academic Editor: Luca Pelà

Received: 20 January 2022

Accepted: 23 February 2022

Published: 25 February 2022

Publisher's Note: MDPI stays neutral with regard to jurisdictional claims in published maps and institutional affiliations.

Copyright: (C) 2022 by the authors. Licensee MDPI, Basel, Switzerland. This article is an open access article distributed under the terms and conditions of the Creative Commons Attribution (CC BY) license (https:// creativecommons.org/licenses/by/ $4.0 /)$.
Abstract: Due to the brittleness, monolithic glass may fracture under impact, resulting in catastrophic sequences. The combined finite-discrete element method, i.e., FDEM, is employed to investigate both the oblique and the perpendicular impact failures of monolithic glass parametrically, particularly the soda-lime glass. Using FDEM, glass is discretised into discrete elements where a finite element formulation is incorporated, leading to accurate evaluation of the contact forces and structural deformation. Following the basic theories of the FDEM, a cohesive Mode I fracture model of glass is briefly introduced. Numerical examples are given for the verification of the employed fracture model and the applicability of the FDEM, and comparisons have been made against the computational and experimental results in the literature. The investigated parameters include the impact velocity, the impact angle, the material properties of glass, etc. The obtained results not only revealed the impact fracture mechanism of soda-lime glass but also provided guidance for its design and manufacturing.

Keywords: glass; impact; fracture; parametric study; combined finite-discrete element method

\section{Introduction}

Glass has been increasingly used as load bearing as well as non-load bearing members in engineering due to its transparent appearances and appealing functions. Among all of the glass types, the soda-lime-silica glass is the most prevalent, and its typical composition is $70 \% \mathrm{SiO}_{2}, 10 \% \mathrm{CaO}$ and $15 \% \mathrm{Na}_{2} \mathrm{O}$ [1]. However, these glass components are brittle and vulnerable to impacts [2]. Under an impact action, glass may fracture into pieces, resulting in catastrophic sequences. Moreover, the flying shards threaten the users greatly and may injury them seriously. Thus, the impact fracture and the post-failure behaviour of glass have attracted growing attention from both the academic and the engineering communities. Endeavours have been made to examine the impact failure of glass for a long time. Early experimental work can be traced to 1920s when Preston [3] revealed that the breakage behaviour of annealed glass is directly related to the appearance of fracture surfaces. This opinion was further backed by Shand [4]. Baird [5] performed a test with a high-speed camera and investigated the stress waves travelling in a glass rod. Hu et al. [6] provided test data for the spherical hard impact fracture of a rectangular glass plate with a polycarbonate backing. Kozłowski [7] presented experimental results on glass balustrades subjected to soft double-tire impact in both the intact and the post-failure (with one glass ply damaged) states. The acceleration of the projectile, stress in glass, and the displacement of balustrades were revealed.

To record the impact fracture processes of glass, high-speed cameras and sensitive sensors are necessary. Further, experiments are expensive and not easy to perform. In 
view of this, numerical simulations have become popular. Among all of the computational approaches, the finite element method (FEM) and the discrete element method (DEM) are the most commonly used. Repetto et al. [8] presented an FE model to evaluate the radial cracking in glass rods, allowing for the crack initiation and propagation in a tension-shear cohesive fashion. Sun et al. [9] implemented a continuum damage mechanics (CDM) model into the commercial FEM package ABAQUS to solve the impact fracture behaviour of glass plies, and the resistance of glass subjects to stone impact was investigated. Grujicic et al. [10] proposed an impact material model considering the high-strain-rate and high-pressure for soda-lime glass, and the model was embedded into the ABAQUS/Explicit. With the developed model, edge-on impact (EOI) on soda-lime glass with a spherical projectile was simulated. In Mohagheghian et al. [11], the responses of chemically strengthened laminated glass window plates subjected to low velocity soft impacts were simulated with ABAQUS/Explicit, showing the energy absorption and peak force reduction. In Kozłowski et al. [12,13], 3D numerical studies on the behaviour of glass subjected to hard-body impact using ABAQUS were performed, reproducing the experiments and retrospectively determining the maximum principal stress in the glass during impact. In general, the FEM can predict the crack initiation and the propagation with reasonable accuracy. However, the crack branching and the post-failure behaviour are highly difficult to simulate with the FEM due to its intrinsic disadvantages.

In addition to the applications with the FEM, the DEM has also been employed in the glass impact fracture analysis. Spherical discrete elements were used by Zang et al. [14], and fracture and fragmentation behaviours of monolithic and laminated glass under rigid ball impacts were investigated. Xu et al. [15] proposed an adaptive combined DE/FE algorithm to simulate the fracture process of brittle material with plane stress assumption. The discrete elements were generated automatically in severely deformed regions, and the model was validated through glass impact fracture simulation. In Baraldi et al. [16], the non-linear discrete element modelling approach was employed to predict the loaddeflection relation of laminated glass from the initial cracking up to the collapse. A recent study [17] examined the glass fracture and the interfacial debonding in laminated glass under impact using a cohesive DE/FE model.

Besides the FEM and the DEM, other numerical methods such as the Extended Finite Element Method (XFEM) [18] and the Peridynamics [19,20] have also been employed in the glass fracture analyses. The combined finite-discrete element method (FDEM) [21] is an extension of both the FEM and the DEM. It was proposed and developed by Munjiza in the 1990s [22]. The structures are fully discretised into a number of discrete elements, in which an FE formulation is incorporated. Thus, accurate evaluation of the contact forces and the structural deformation can be obtained, leading to a rational manner of crack development. In this study, the FDEM program ' $Y$ ' using the Munjiza-NBS contact detection algorithm [23] and a cohesive cracking model [24] was employed to simulate the impact fracture of glass. Cracks are assumed to initiate and propagate along element edges [25], and mesh bias can be relieved should fine mesh with irregular orientations be used [26]. Further information on the FDEM can be referred to in the work of Munjiza and his co-workers $[27,28]$. The FDEM has previously been applied to the quasi-static and dynamic analysis of brittle solids [29-33]. Early work [34,35] addressed the impact fracture simulations on the monolithic and the laminated glass with the FDEM. Hard body impact damage modes like flexural cracking, Hertzian cone failure, and punching were obtained by Chen et al. [36] with the FDEM, and the breakage regimes were identified. Subsequent research addressed the capability of the FDEM in modelling the failure of laminated glass subjected to both hard and soft body impacts [37,38]. In Munjiza et al. [39], impact fracture and the post-failure of 3D glass shells were presented using the FDEM elements. A recent paper [40] introduced a generalised traction-separation model and simulated the impact fracture process of glass beams and plates.

Although there are some applications on the glass impact fracture using the FDEM, a comprehensive parametric study is still in demand and warranted. As a sequel to the 
previous work [36], a parametric investigation into the impact fracture of monolithic glass (especially the soda-lime glass) using the FDEM was conducted in this study, and an insight into the glass impact fracture mechanism was provided. The emphasis of this research is given to the annealed glass (float glass). The layout for the rest of this paper is as follows. In Section 2, the fundamentals of the FDEM are briefly introduced. The glass fracture model used in the FDEM simulation is addressed in Section 3. Section 4 presents numerical examples for verification purposes. In Section 5, a convergence study on the impact fracture patterns, projectile velocity and the total kinetic energy of different meshes is conducted. Based on the selected base case, a comprehensive investigation was performed over a variety of parameters, including the impact velocity, the impact angle, the material properties of glass, etc. Finally, concluding remarks are reached in Section 6.

\section{The Combined Finite-Discrete Element Method}

\subsection{Element Motions}

Motions of elements in the FDEM are determined by Newton's second law of motion. Since the transient dynamic responses are much larger than the gravitational effect during impact, the gravities of both the glass and the projectile are neglected. The translational and the rotational governing equations of a single discrete element $i$ are formulated as

$$
\begin{gathered}
m_{i} \frac{d^{2}}{d t^{2}} \boldsymbol{r}_{i}=\boldsymbol{F}_{i} \\
I_{i} \frac{d}{d t} \boldsymbol{\omega}_{i}=\boldsymbol{T}_{i}
\end{gathered}
$$

where $m_{i}$ is the mass of the discrete element $i ; \boldsymbol{r}_{i}$ is the vector of position; $I_{i}$ is the inertia moment; $\boldsymbol{\omega}_{i}$ is the angular velocity; $\boldsymbol{F}_{i}$ is the net external force; and $\boldsymbol{T}_{i}$ is the net external torque. At each time step, the velocity and the coordinate of any discrete element can be explicitly obtained according to Equations (1) and (2).

\subsection{Contact Agorithm}

The contact algorithm is categorised as the contact detection and the contact interaction. The Munjiza-NBS contact detection algorithm [23] is employed in the FDEM, and the computational efficiency is linearly related to the element number. Further details on the Munjiza-NBS algorithm can be referred to Refs. [21,23].

Once contact couples are detected, contact interaction follows and determines the contact forces. In the 2D FDEM, the contact forces are calculated based on the overlapping area $S$ (Figure 1). The penetration of area $d A$ yields an infinitesimal contact force $d \mathbf{f}$, as given by Equation (3).

$$
d \mathbf{f}=-d \mathbf{f}_{\mathbf{t}}+d \mathbf{f}_{\mathrm{C}}
$$

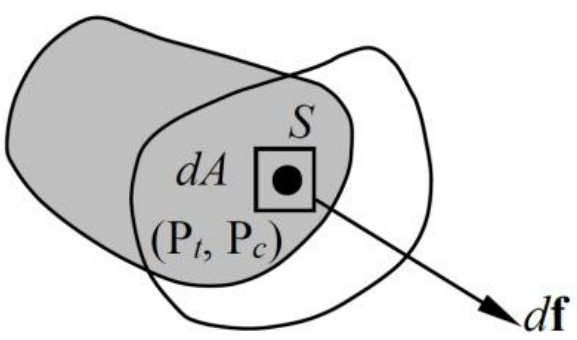

Figure 1. Contact force evaluation in the 2D FDEM.

The subscripts ' $\mathrm{t}$ ' and ' $\mathrm{c}$ ' refer to the target and the contactor, respectively. $d \mathbf{f}_{\mathrm{t}}$ and $d \mathbf{f}_{\mathrm{c}}$ are defined in Equations (4) and (5), as

$$
d \mathbf{f}_{\mathrm{t}}=-E_{p} \operatorname{grad} \varphi_{c}\left(\mathrm{P}_{c}\right) d A
$$




$$
d \mathbf{f}_{\mathrm{c}}=-E_{p} \operatorname{grad} \varphi_{t}\left(\mathrm{P}_{t}\right) d A
$$

where $\mathrm{P}_{c}$ and $\mathrm{P}_{t}$ are the points on the contactor and the target sharing the same coordinate on $S ; \varphi_{c}$ and $\varphi_{t}$ are pre-defined potentials; grad is short for gradient; $E_{p}$ is the contact penalty and is normally 2 to 100 times larger than the first lame constant $\lambda=\frac{E v}{(1+v)(1-2 v)} ; E$ is the elastic modulus; and $v$ is the Poisson's ratio. By integrating $d A$ over $S$, the contact force $\mathbf{f}$ is obtained in Equation (6). The contact detection and the contact interaction processes are updated every time step automatically by the FDEM.

$$
\mathbf{f}=E_{p} \int_{S}\left[\operatorname{grad} \varphi_{c}\left(\mathrm{P}_{c}\right)-\operatorname{grad} \varphi_{t}\left(\mathrm{P}_{t}\right)\right] d A
$$

\subsection{Joint Element}

Constant strain triangular (CST) elements are available to the present authors in the 2D FDEM. Between each pair of CST elements in connection, four-node joint elements are defined (Figure 2) and fracture models are implemented. The deformation of joint elements $(\delta)$ determines the transition of material from continua to discontinua. Initially, the joint element is a zero-thickness line when $\delta=0$. After deformation, it becomes a quadrilateral with $\delta>0$. When $\delta$ reaches a threshold, two connected discrete elements separate completely, and the material fractures.

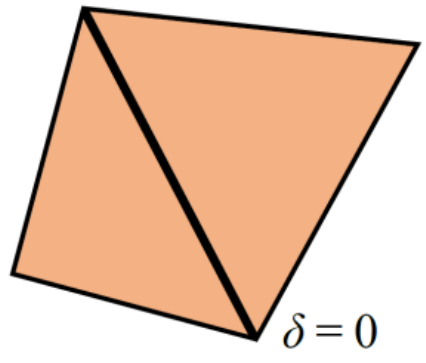

(a)

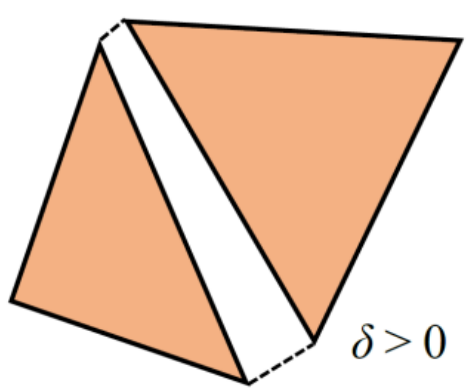

(b)

Figure 2. Joint element: (a) before deformation; (b) after deformation.

\section{Fracture Model of Glass}

Basically, glass is ideally brittle and follows Mode I fracture [41]. To account for the rupture of glass computationally, a cohesive fracture model based on Hillerborg's [42] is employed in this study. With this model, the brittleness of glass can be described, and the computational stability can be guaranteed. A crack is considered to develop once the bonding stress $\sigma$ reaches the tensile strength $f_{t}$, indicating the start of the damage. Meanwhile, $\delta$ reaches its elastic limit, i.e., $\delta=\delta_{p}$. With the increase of the deformation of the joint element, the bonding stress $\sigma$ decreases gradually. When $\delta$ equals its ultimate value $\delta_{c}, \sigma=0$ and the cracking process is completed. This process is considered as 'strain softening', and the area between the softening curve and the coordinate axes equals the fracture energy $G$, as given by Equation (7).

$$
\mathrm{G}=\int_{\delta_{p}}^{\delta_{c}} \sigma d \delta
$$

Prior to reaching the tensile strength of the material, standard continuum formulation (FEM) is adopted. The cohesive fracture model is capable of capturing the damage through a weak constitutive law, enabling the cracks to be smeared out over the continuum. The breakage of glass fully depends on the stress distribution of the material since no predefined cracks or notches are necessary. 
The complete relation between the bonding stress $\sigma$ and the joint element deformation $\delta$ is given in Equation (8) according to Munjiza [21].

$$
\sigma= \begin{cases}{\left[2 \frac{\delta}{\delta_{p}}-\left(\frac{\delta}{\delta_{p}}\right)^{2}\right] f_{t}} & 0 \leq \delta \leq \delta_{P} \\ f_{t} z & \delta_{P}<\delta \leq \delta_{c}\end{cases}
$$

The heuristic parameter $z$ has the form of

$$
z=\left[1-\frac{a+b-1}{a+b} e^{D(a+b c /((a+b)(1-a-b)))}\right]\left[a(1-D)+b(1-D)^{c}\right]
$$

where $D$ is a fracture index within the interval $[0,1] . D=0$ suggests that the joint element is undeformed and intact, while $D=1$ implies the total damage of the joint element and the free movement of corresponding discrete element couples. The expression of index $D$ is given in Equation (10).

$$
D=\left\{\begin{array}{cc}
\left(\delta-\delta_{p}\right) /\left(\delta_{c}-\delta_{p}\right) & \delta_{p}<\delta \leq \delta_{c} \\
1 & \delta>\delta_{c}
\end{array}\right.
$$

In Equation (9), parameters $a, b$ and $c$ are constants. It is verified that, for glass, $a=1.2$, $b=-1.0$ and $c=1.0$ [36]. Based on the above definitions, the normalised strain softening curve of glass is given in Figure 3.

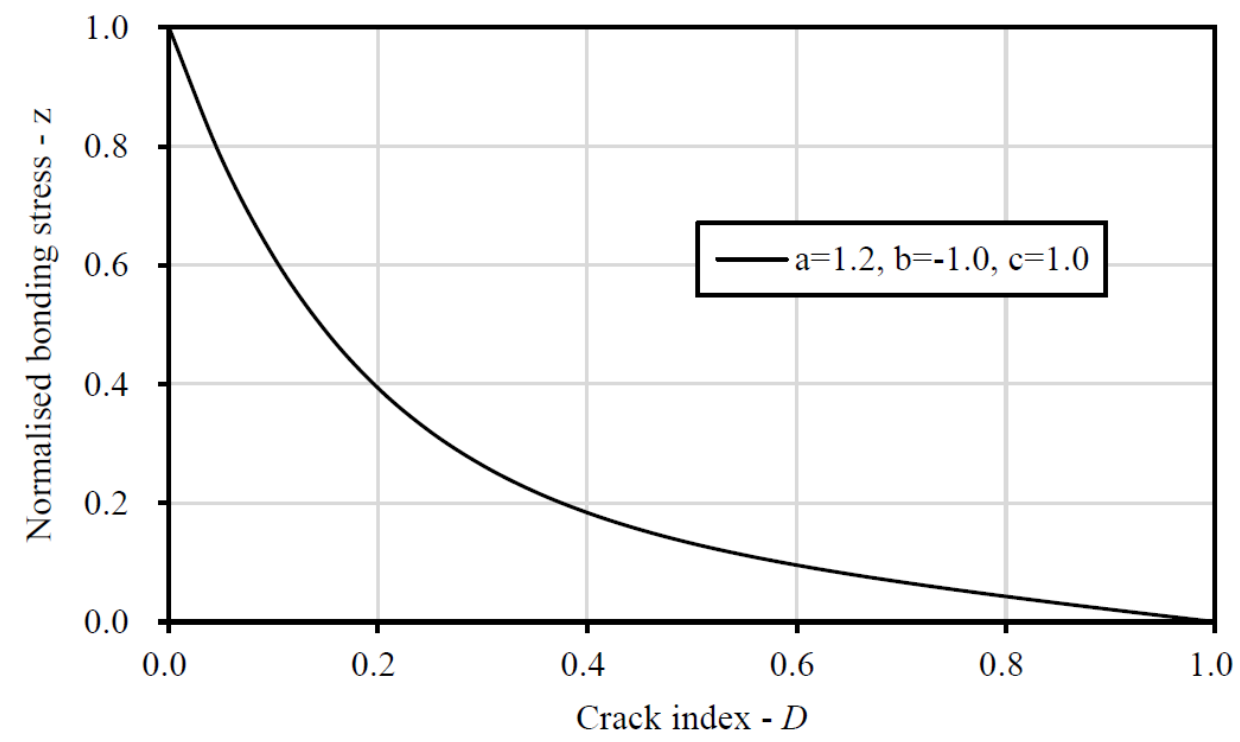

Figure 3. The normalised strain softening curve of glass.

\section{Verification}

\subsection{Comparison with DEM}

In Zang et al. [14], the impact damage and the post-failure behaviour of single-layer glass were analysed using spherical discrete elements. A 2D FDEM analysis is conducted in this study. The glass beam is $101 \mathrm{~mm} \times 4.76 \mathrm{~mm}$ and both ends are clamped. There are 6080 CST elements with a characteristic size of $0.4036 \mathrm{~mm}$ within the glass. The time step is $1.0 \times 10^{-10} \mathrm{~s}$. A $1.0 \mathrm{~kg}$ projectile with a radius of $6 \mathrm{~mm}$ impacts the centre of the glass at an initial velocity of $30.0 \mathrm{~m} / \mathrm{s}$. The material properties used in the FDEM simulation are presented in Table 1, and the values of glass are based on [14]. 
Table 1. Material properties used in the FDEM analysis.

\begin{tabular}{ccc}
\hline & Glass & Projectile \\
\hline Density $\left(\mathrm{kg} / \mathrm{m}^{3}\right)$ & 2500 & 8841.9 \\
Young's modulus $(\mathrm{GPa})$ & 74.1 & 200.0 \\
Poisson's ratio & 0.2 & 0.3 \\
Tensile strength $(\mathrm{MPa})$ & 34.6 & not applicable \\
Shear strength $(\mathrm{MPa})$ & 17.9 & not applicable \\
Fracture energy $(\mathrm{N} / \mathrm{m})$ & 4.0 & not applicable \\
\hline
\end{tabular}

Figure 4 shows the damage processes obtained from both the FDEM and the DEM [14] in the equivalent scale. The failure responses of glass are similar. The impactors penetrate the glass beam, and their vertical displacements are in good agreement, implying that the velocities of the projectiles are similar. Further, the sizes of the damaged zones obtained by the two methods are also close to each other. The fragmentation has also been captured but with some differences. Some large pieces of fragments are found in the FDEM simulation, while most of them are linked particles in the DEM modelling. It can be concluded that a better structural behaviour is achieved since CST elements are used in the FDEM. On the other hand, CST elements may introduce higher rigidity in the FDEM simulation, whilst the fragments and the fragmentation seem much softer in the DEM simulation, owing to flexible particle connections.

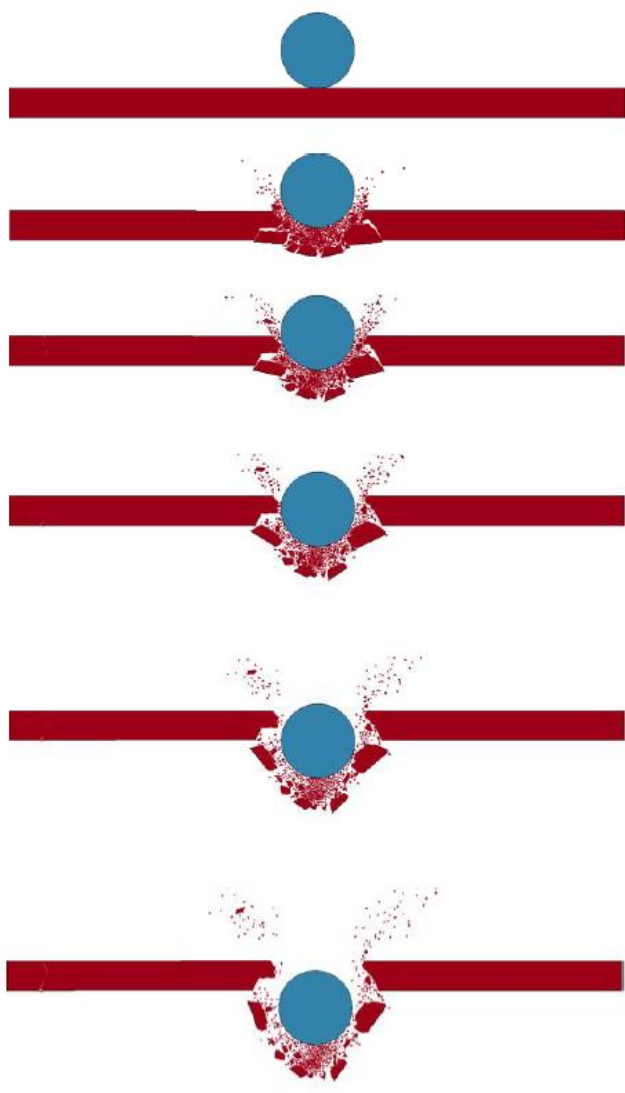

(a)
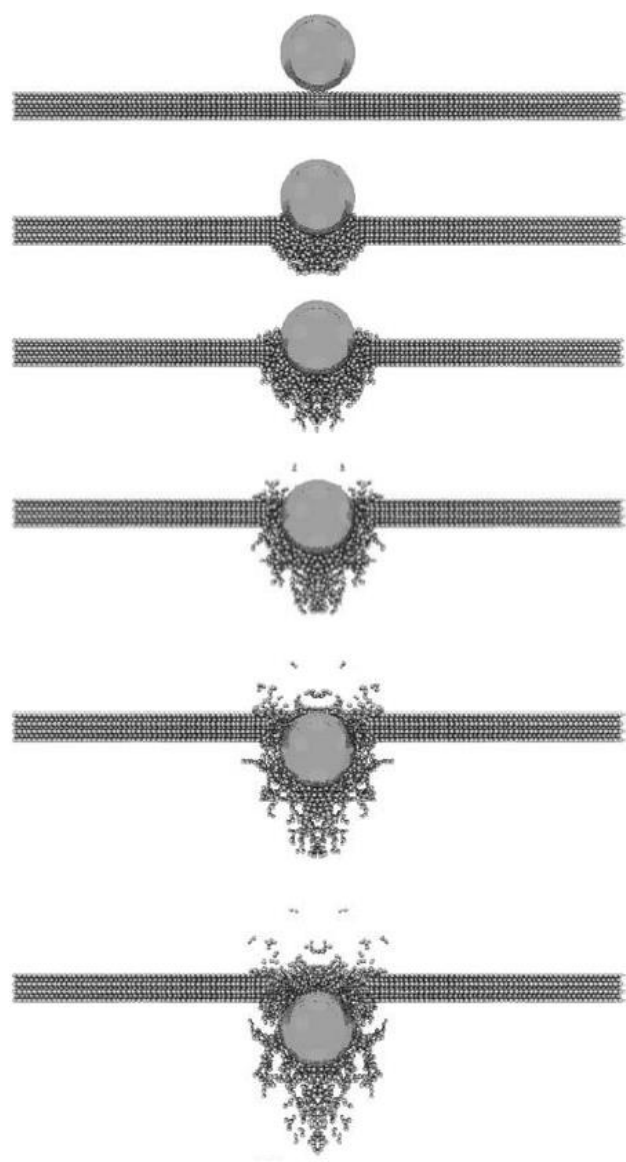

(b)

Figure 4. Failure sequences at $\mathrm{t}=0,0.1,0.2,0.3,0.4,0.5 \mathrm{~ms}$ : (a) FDEM; (b) DEM (Adapted from Ref. [14]). 


\subsection{Comparison with Peridynamics}

Ha [43] performed dynamic fracture analysis for multi-layered glass structures using the peridynamics. A three-point bending laminated glass is considered with the dimensions shown in Figure 5a. Each glass layer is $3 \mathrm{~mm}$, and the Polyvinyl Butyral (PVB) interlayer is $0.19 \mathrm{~mm}$. The PVB and the glass are well bonded, suggesting that there is no potential debonding between them. The centre of the top surface is subjected to a variable vertical velocity $v$, and its definition is given in Figure $5 b$. Based on Ha [43], the PVB interlayer is considered strong enough to resist impact fracture, and, hence, the failure of the laminated glass is solely attributed to the fracture of glass. The material properties used in the FDEM analysis are presented in Table 2 . There are 4436 elements in total, and the characteristic element size of the laminated glass is $0.3 \mathrm{~mm}$. The mesh configuration is shown in Figure 6 . The time step for the FDEM analysis is $1.0 \times 10^{-10} \mathrm{~s}$.

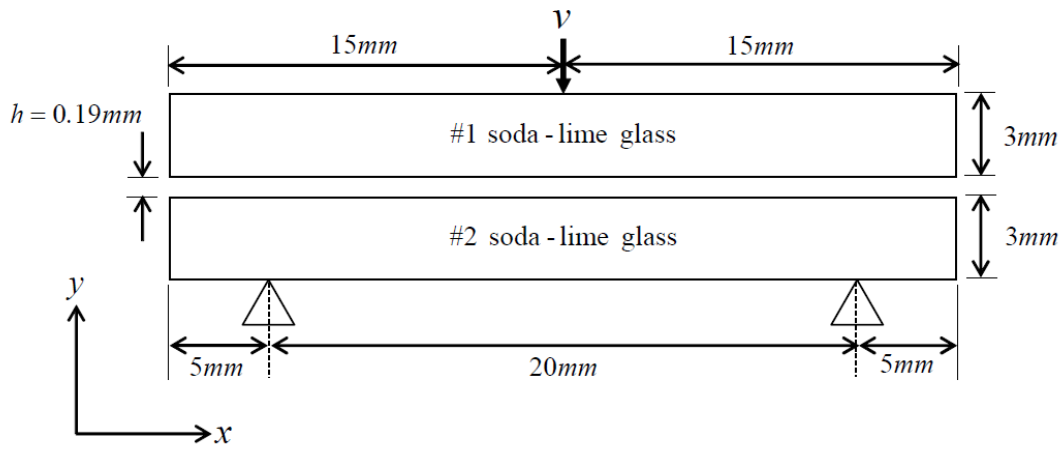

(a)

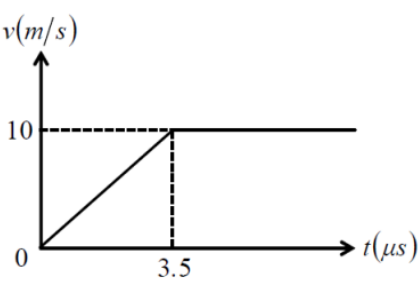

(b)

Figure 5. The impact of the laminated glass (Reprinted from Ref. [43]): (a) The dimension; (b) Loading condition.

Table 2. Material properties used in the laminated glass analysis.

\begin{tabular}{ccc}
\hline & Glass & Interlayer \\
\hline Density $\left(\mathrm{kg} / \mathrm{m}^{3}\right)$ & 2440.0 & 1100.0 \\
Young's modulus $(\mathrm{GPa})$ & 72.0 & 0.1 \\
Poisson's ratio & 0.2 & 0.48 \\
Tensile strength $(\mathrm{MPa})$ & 34.6 & not applicable \\
Fracture energy $(\mathrm{N} / \mathrm{m})$ & 4.0 & 940.0 \\
\hline
\end{tabular}

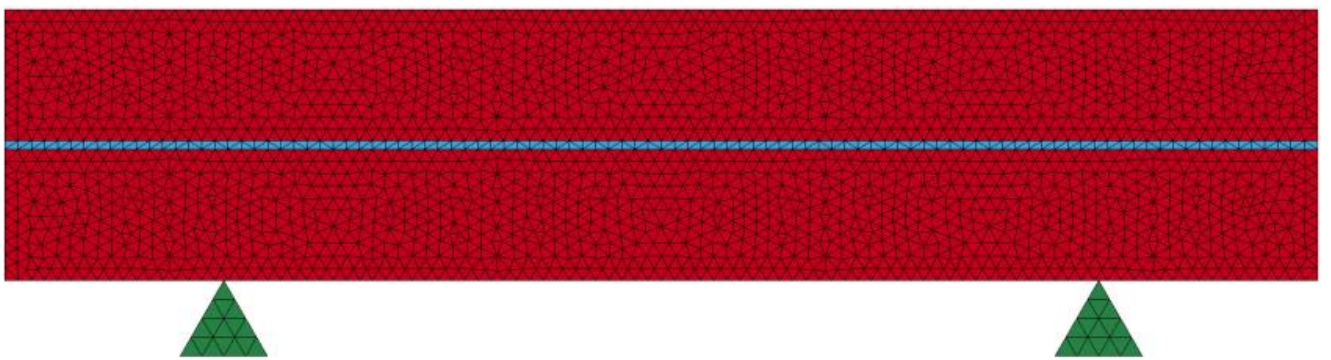

Figure 6. Mesh configuration for the FDEM analysis.

Figure 7 shows the damage pattern of the laminated glass at $t=7.5 \mu \mathrm{s}$ from both the FDEM and the peridynamics. It is found that, in the FDEM simulation, a through-thickness crack has formed in the upper glass layer, reaching good agreement with the result obtained by the peridynamics. In addition to the dominant through-thickness crack in the upper glass layer, local damage with fragments is observed around the impact point in the FDEM simulation, and this is not available in the peridynamics analysis. Once the glass around the 
impact point fractures in the FDEM simulation, the position of the loading point changes, suggesting that the following result cannot be equivalently compared with that from the peridynamics, and, hence, only the damage at $t=7.5 \mu \mathrm{s}$ is presented. Nevertheless, the comparison shows that the FDEM result is verified with the peridynamic data.

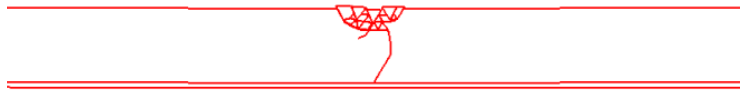

(a)

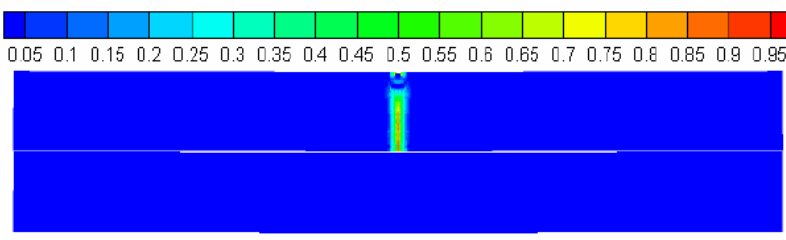

(b)

Figure 7. Damage of the laminated glass at $t=7.5 \mu \mathrm{s}$ : (a) FDEM; (b) Peridynamics (Adapted from Ref. [43]).

\subsection{Comparison with Experiment}

$\mathrm{Xu}$ and Zang [44] examined the impact fracture of a laminated glass beam constrained by four fixed supporters experimentally. The dimensions of the beam are $200 \mathrm{~mm} \times$ $24 \mathrm{~mm} \times 10 \mathrm{~mm}$, as shown in Figure 8a. The thicknesses of the upper and lower glass layers are both $10 \mathrm{~mm}$, and the thickness of the PVB interlayer is $4 \mathrm{~mm}$. The projectile is $4 \mathrm{~mm} \times 4 \mathrm{~mm} \times 10 \mathrm{~mm}$ with a mass of $1.0 \mathrm{~kg}$ and impacts the middle of the glass at a velocity of $3.13 \mathrm{~m} / \mathrm{s}$. Same as that in Section 4.2 , the interlayer is also assumed to be non-fractured and in perfect bond with the glass. The mesh configuration is shown in Figure $8 \mathrm{~b}$. In total, 10106 elements with a characteristic size of $1 \mathrm{~mm}$ are meshed within the laminated glass body. According to $\mathrm{Xu}$ and Zang [44], the material properties used in the FDEM analysis are given in Table 3 . The time step is $5.0 \times 10^{-10} \mathrm{~s}$.

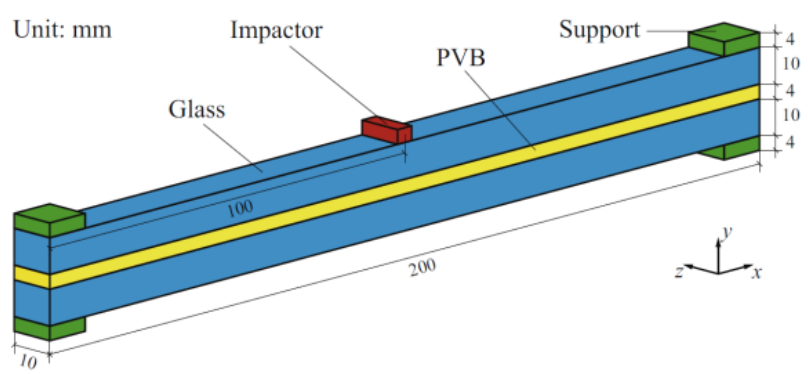

(a)

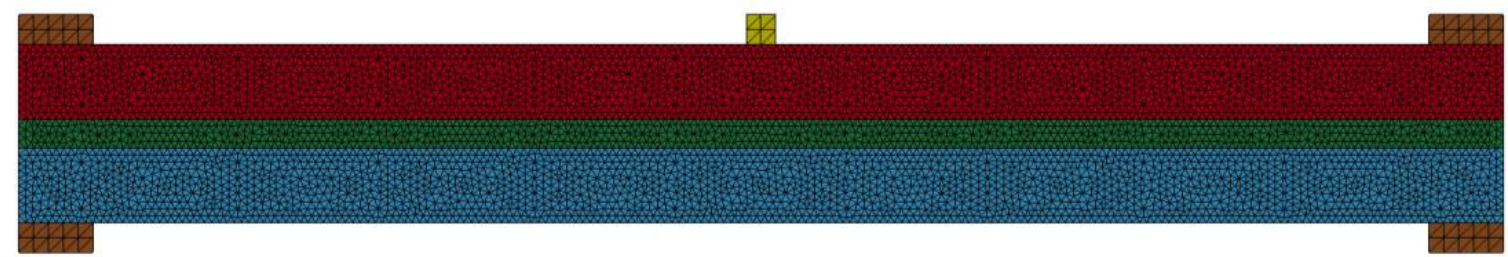

(b)

Figure 8. Configurations of the laminated glass: (a) Geometry (Adapted from Ref. [44]); (b) FDEM mesh.

Figure 9 shows the snapshots of the failure sequences from both the FDEM and the experiment [44] starting from $t=0 \mathrm{~s}$ with a $100 \mu$ s interval. At the early stage $(t=100-200 \mu \mathrm{s})$, glass fails just below the projectile in the upper glass, and the cracks propagate along the thickness. A dominant bending crack is found in the lower glass layer at around $t=300 \mu \mathrm{s}$ and develops further towards the interlayer along with the development of time. The final captured damage pattern at $t=500 \mu$ s shows that some small fragments have formed near the contact surface. 
Table 3. Material properties for the FDEM analysis.

\begin{tabular}{lcccc}
\hline & Glass & Interlayer & Projectile & Supporter \\
\hline Density $\left(\mathrm{kg} / \mathrm{m}^{3}\right)$ & 2500.0 & 100.0 & - & 2400.0 \\
Young's modulus $(\mathrm{GPa})$ & 74.09 & 0.05 & 210.0 & 5.0 \\
Poisson's ratio & 0.2 & 0.48 & 0.269 & 0.4 \\
Tensile strength $(\mathrm{MPa})$ & 100.0 & - & - & - \\
Fracture energy $(\mathrm{N} / \mathrm{m})$ & 10.0 & - & - \\
-: not applicable. & & & & -
\end{tabular}

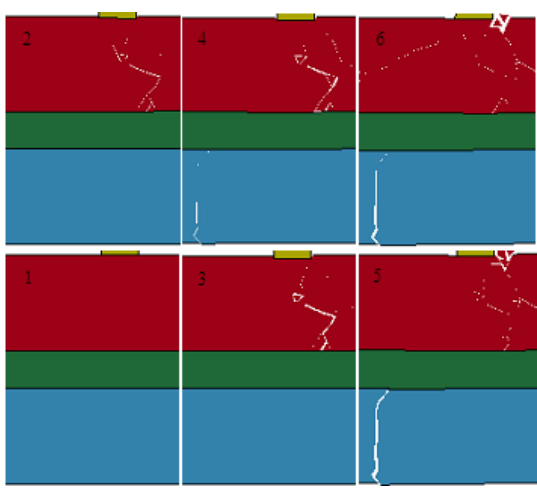

(a)
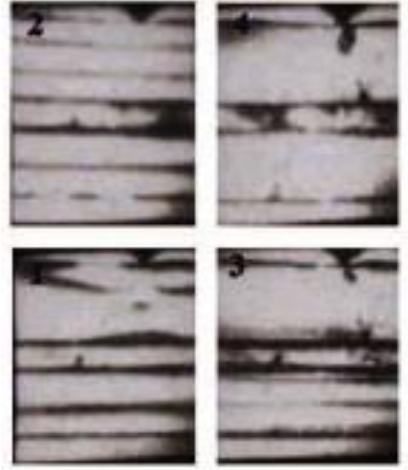

(b)
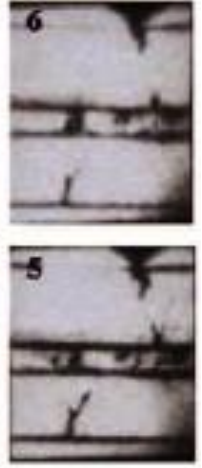

Figure 9. Impact fracture results: (a) FDEM; (b) Experiment (Adapted from Ref. [44]).

The FDEM simulation agrees very well with the experimental snapshots. Cracks are observed in the upper glass, and a dominant bending crack has formed at a similar location and time as in the experimental records. Figure 10 shows the change of the vertical projectile velocity against time from the FDEM simulation. It can be seen that the velocity is in monotonic descending, and the residual velocity at $t=500 \mu \mathrm{s}(v=2.82 \mathrm{~m} / \mathrm{s})$ is about $90 \%$ of the initial impact velocity, suggesting that the projectile can further damage the laminated glass should the FDEM simulation proceed.

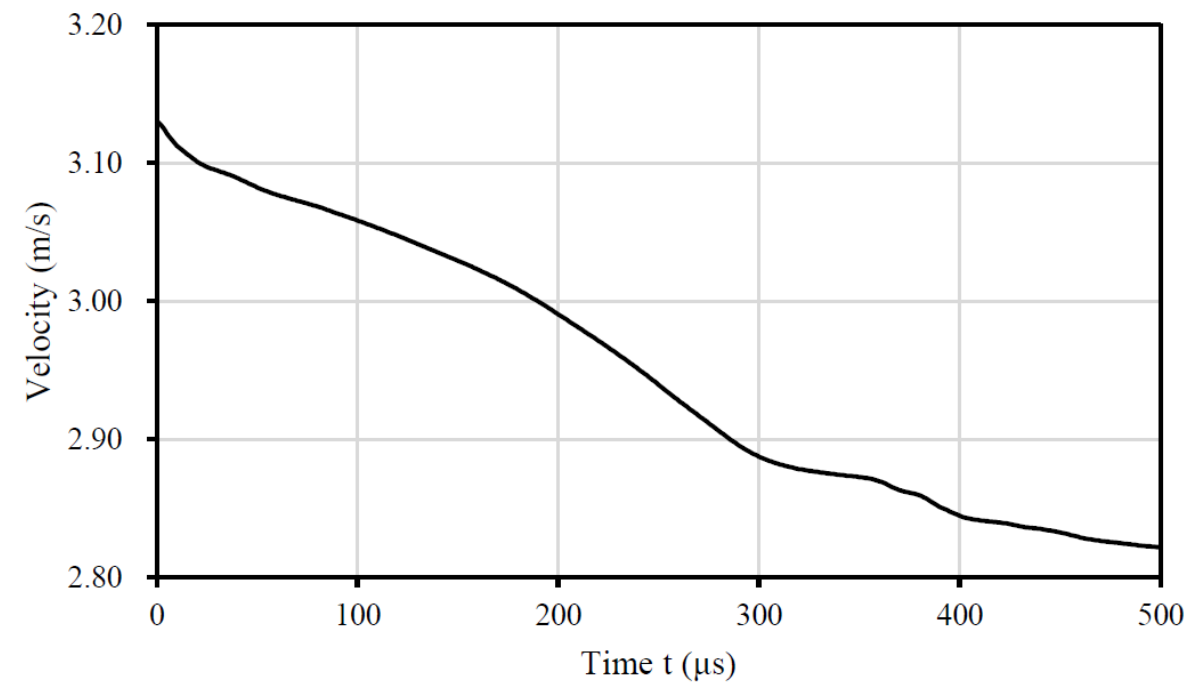

Figure 10. Vertical velocity of the projectile.

\section{Parametric Study}

\subsection{Mesh Convergence}

Considering a glass beam $1 \mathrm{~m}$ long and $20 \mathrm{~mm}$ thick, both ends are constrained by two L-shaped supports (Figure 11). The beam is subject to the impact of a circular projectile 
with a $20 \mathrm{~mm}$ radius. To study the convergence of the impact responses with different meshes, Mesh A and B are employed in this study, and the details of the meshes (the length of the coarse and the fine regions, i.e., $L_{\text {coarse }}$ and $L_{\text {fine, }}$, and the corresponding characteristic size $\Delta h$ ) are given in Table 4 . For commonly used annealed soda-lime glass, the density $\rho=2500 \mathrm{~kg} / \mathrm{m}^{3}$, the Young's modulus $E=70 \mathrm{GPa}$ and the Poisson's ratio $v=0.23$. The tensile strength varies in the range of 20 to $100 \mathrm{MPa}$ depending on its specific type [45-48]. According to the previous research [36], $f_{t}=30 \mathrm{MPa}$ can be considered as the mean tensile strength for glass. Regarding the fracture energy, $G=4.0 \mathrm{~N} / \mathrm{m}$ is widely accepted and used [49-51]. Thus, the material properties are tabulated in Table 5. The time step of the FDEM simulations is $2.5 \times 10^{-9} \mathrm{~s}$.

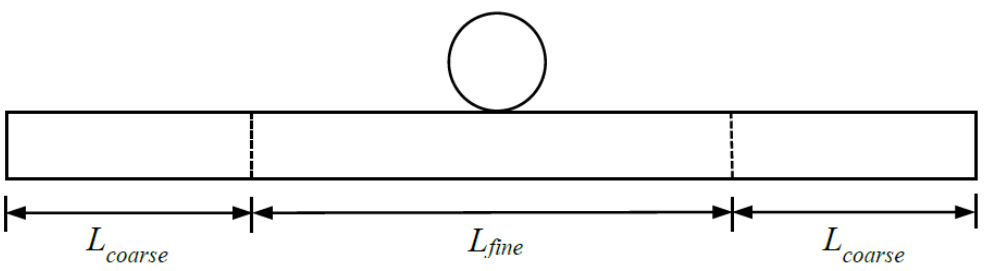

Figure 11. Glass impact configurations.

Table 4. Element details of Mesh A and B.

\begin{tabular}{ccc}
\hline & Mesh A & Mesh B \\
\hline$L_{\text {fine }}(\mathrm{m}) / \Delta h(\mathrm{~m})$ & $0.4 / 0.001$ & $1.0 / 0.001$ \\
$L_{\text {coarse }}(\mathrm{m}) / \Delta h(\mathrm{~m})$ & $0.3 / 0.005$ & - \\
Total number of elements & 19,070 & 43,030 \\
\hline
\end{tabular}

Table 5. Material properties for FDEM simulations.

\begin{tabular}{ccc}
\hline & Glass & Projectile/Support \\
\hline Young's modulus $(\mathrm{GPa})$ & 70.0 & 200.0 \\
Poisson's ratio & 0.23 & 0.3 \\
Density $\left(\mathrm{kg} / \mathrm{m}^{3}\right)$ & 2500.0 & 7800.0 \\
Tensile strength $(\mathrm{MPa})$ & 30.0 & - \\
Shear strength $(\mathrm{MPa})$ & 15.0 & - \\
Facture energy $(\mathrm{N} / \mathrm{m})$ & 4.0 & - \\
\hline
\end{tabular}

Figure 12 shows the damage patterns of the glass beam subjected to different impact velocities with different meshes at $t=1 \mathrm{~ms}$. When the impact velocity is low, e.g., $v=2 \mathrm{~m} / \mathrm{s}$ in this case, only some local damages around the impact point and a through-thickness flexural crack are obtained. A notable Hertzian cone cracking is identified when $v=7 \mathrm{~m} / \mathrm{s}$. For impact with $v=30 \mathrm{~m} / \mathrm{s}$, the projectile penetrates into the glass deeply, and a crushing failure is observed. The fracture patterns of Mesh A and B at different impact velocities are highly similar, qualitatively demonstrating the convergence of the FDEM results. To verify the convergence of the FDEM results with different meshes quantitively, time histories of the vertical velocity of the projectile and the normalised total kinetic energy (normalised to its initial value) are plotted in Figure 13. According to Figure 13, the curves of Mesh A and $\mathrm{B}$ are in good agreement and quite close to each other in general, and, thus, the mesh convergence is quantitively verified. 
Mesh A
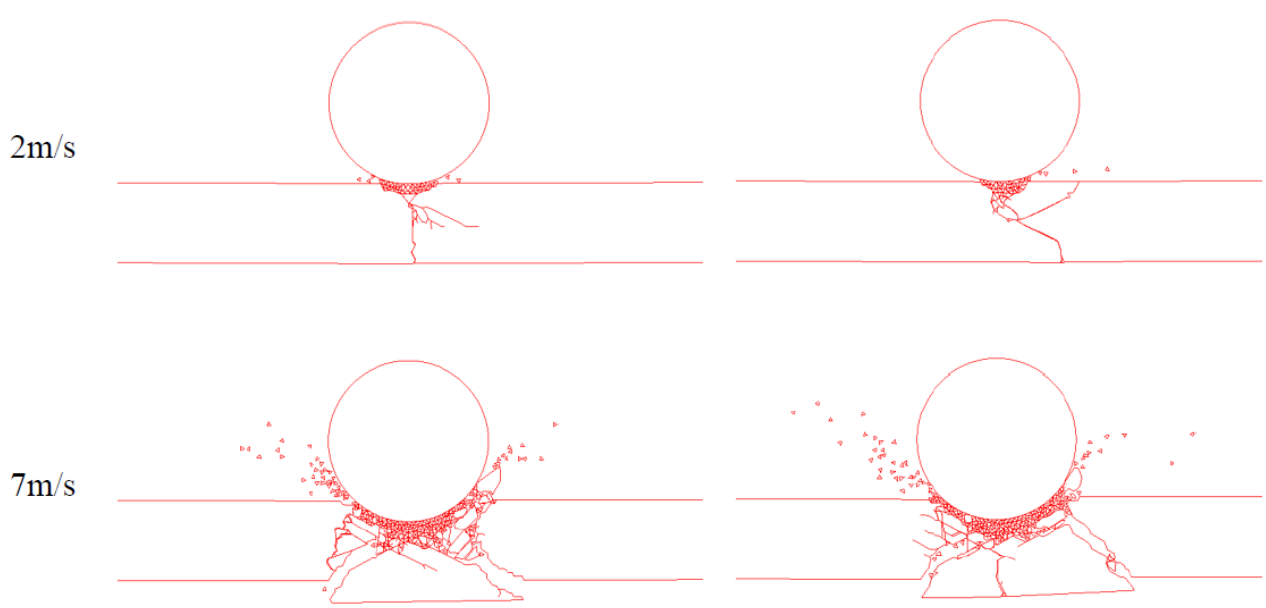

$30 \mathrm{~m} / \mathrm{s}$

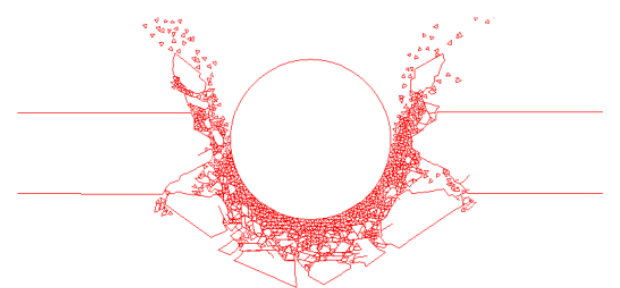

Mesh B
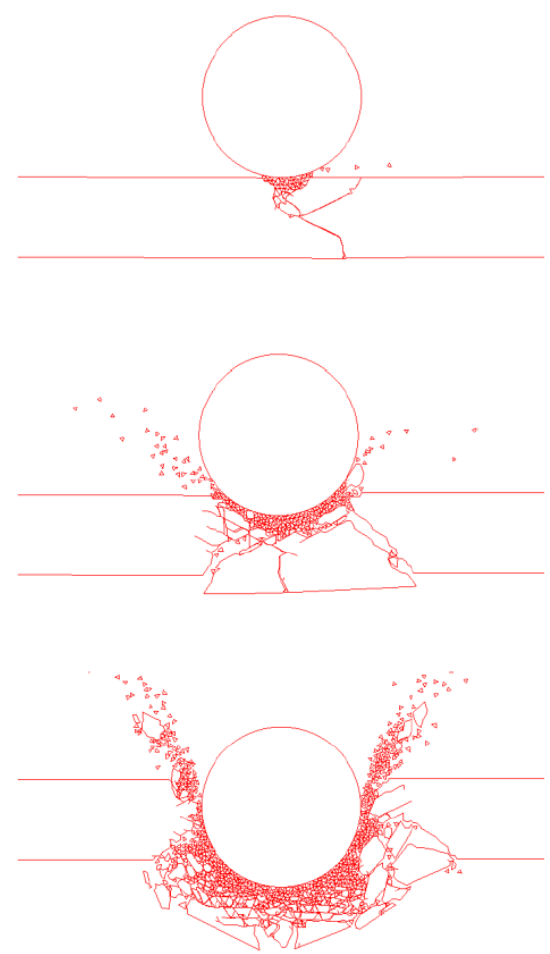

Figure 12. Damage patterns of the glass with different meshes at $t=1 \mathrm{~ms}$.
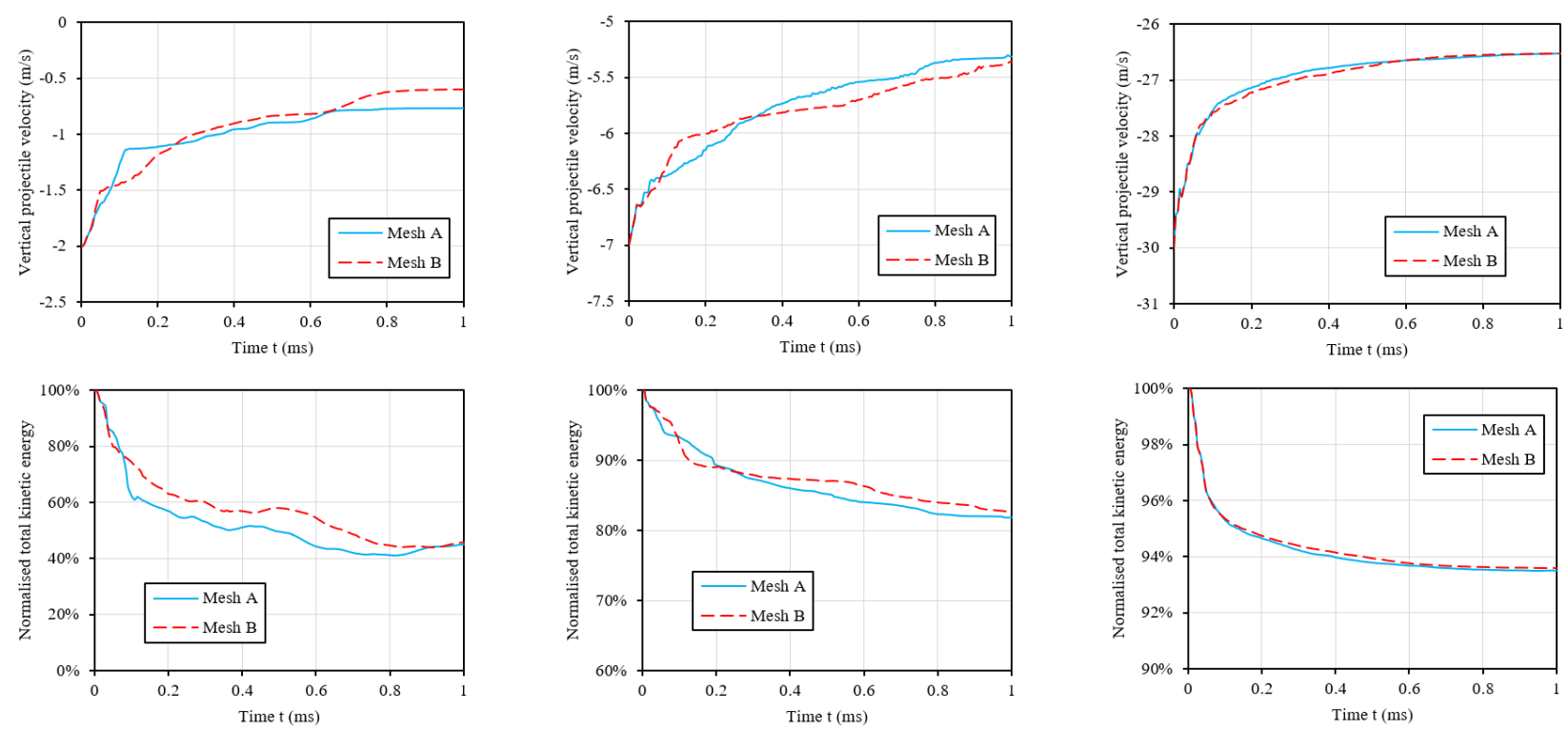

(a)

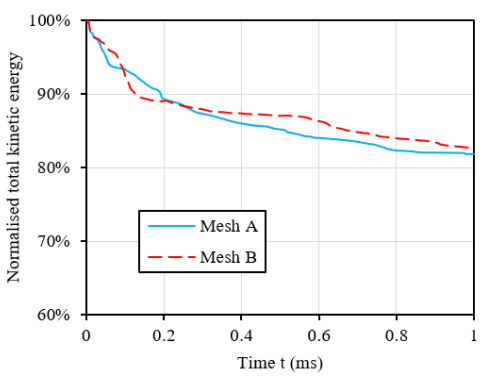

(b)

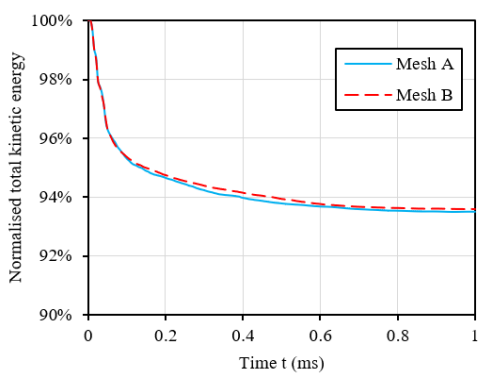

(c)

Figure 13. Time histories of impact responses: (a) $v=2 \mathrm{~m} / \mathrm{s}$; (b) $v=7 \mathrm{~m} / \mathrm{s} ;(\mathbf{c}) v=30 \mathrm{~m} / \mathrm{s}$.

\subsection{Impact Velocity}

Consider the glass beam and the projectile with Mesh A as the base case that will be used in the following parametric investigations. The impact velocity $v$ varies from low to high, e.g., 1 to $30 \mathrm{~m} / \mathrm{s}$. Figure 14 shows the impact damage patterns of the glass beam simulated by the FDEM at $t=1 \mathrm{~ms}$. When the impact velocity is low, i.e., $v=1 \mathrm{~m} / \mathrm{s}$, there are only some local minor damages around the impact point, whilst the majority of the beam is intact, as can be seen in Figure 14a. With the increase of the impact velocity, the 
flexural deformation increases, and a dominant through-thickness bending crack appears (Figure 14b). A Hertzian cone cracking is achieved should the impact velocity further increase within the range of 4 to $10 \mathrm{~m} / \mathrm{s}$ (Figure 14c,d). When the impact velocity is in the range of 10 to $15 \mathrm{~m} / \mathrm{s}$, the cone cracks are no longer typical and are difficult to be identified in general, as, once a cone forms, it quickly vanishes since the residual impact velocity is high enough to push the projectile to move further. This stage is the transition from typical cone fracture to punching failure. When the impact velocity reaches $20 \mathrm{~m} / \mathrm{s}$, typical punching failure dominates, and the glass beam quickly fractures into small fragments due to the overwhelming impact kinetic energy from the projectile.

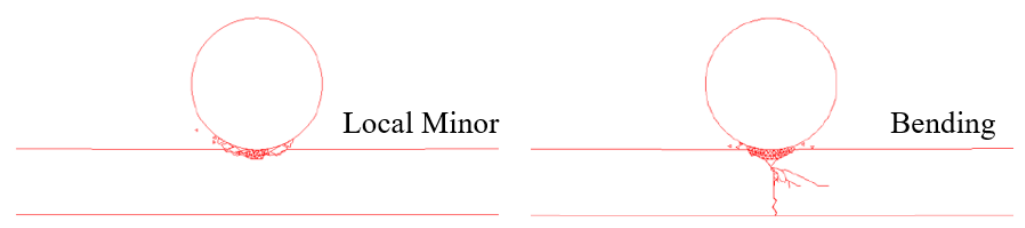

(a) $v=1 \mathrm{~m} / \mathrm{s}$

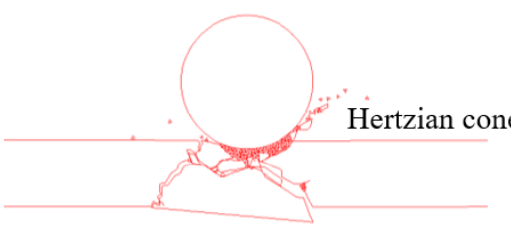

(c) $v=4 \mathrm{~m} / \mathrm{s}$

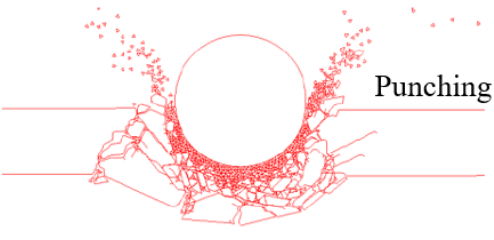

(e) $v=20 \mathrm{~m} / \mathrm{s}$ (b) $v=2 \mathrm{~m} / \mathrm{s}$

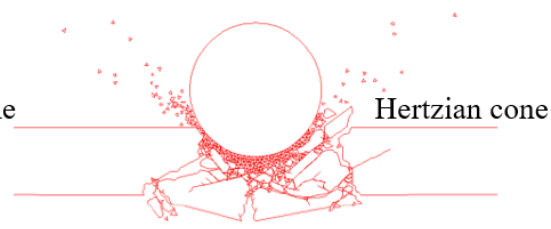

(d) $v=10 \mathrm{~m} / \mathrm{s}$

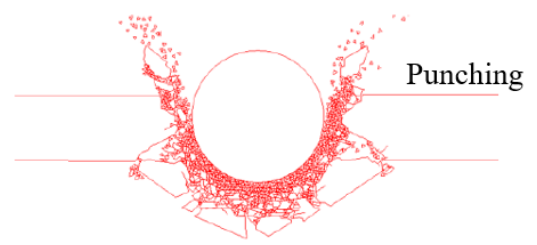

(f) $v=30 \mathrm{~m} / \mathrm{s}$

Figure 14. Damage patterns of the glass beam with different impact velocities at $t=1 \mathrm{~ms}$.

Based on the observations of the glass impact failure patterns simulated by the FDEM, the correlations between the impact velocity and the corresponding impact failure mode are presented in Table 6. A conclusion is reached that, with the increase of the impact velocity, the glass beam experiences four different types of damage, as shown in Figure 14: (i) local minor damage; (ii) bending failure; (iii) Hertzian cone cracking; (iv) punching. The breakage regimes of the four types of damage and the thresholds have been given by Chen et al. [36]. Considering the correlations between the impact velocity and the failure mode in this study, and mapping the currently obtained data points into the graphs of breakage regimes [36], a very good agreement is achieved, as shown in Figure 15. For a specific impact failure in this study, its fracture resistance $(\mathrm{G} h)$ and the impact kinetic energy $\left(m v^{2} / 2\right)$ situate well in the corresponding regime given in the previous research [36], further demonstrating the reliability and robustness of the FDEM in performing the parametric investigations.

Table 6. The correlations between the impact velocity and the impact failure mode.

\begin{tabular}{cc}
\hline Impact Velocity $(\mathrm{m} / \mathbf{s})$ & Impact Failure Mode \\
\hline$<1$ & Local minor \\
2 to 3 & Bending \\
4 to 15 & Cone \\
$>15$ & Punching \\
\hline
\end{tabular}




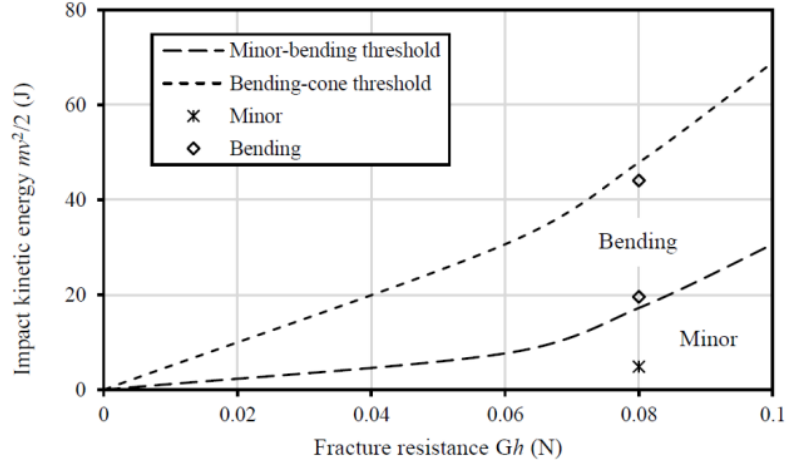

(a)

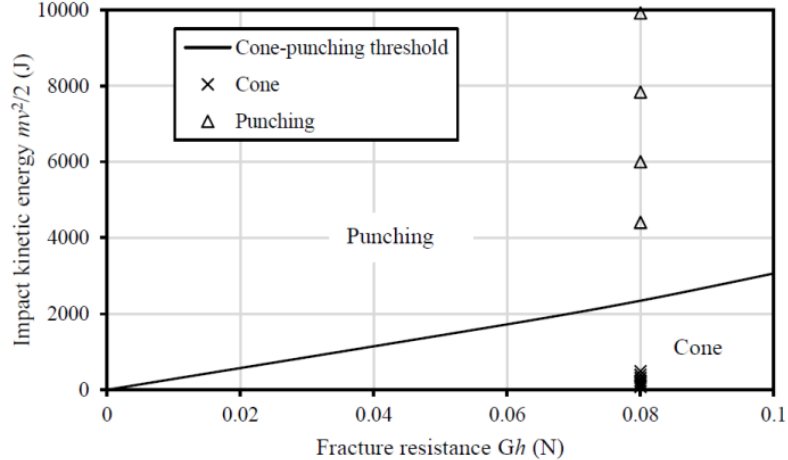

(b)

Figure 15. Breakage regimes and the mapping of failure points: (a) minor and bending damage; (b) cone and punching failure.

\subsection{Impact Angle}

In previous studies, the projectile hits the glass in a perpendicular manner. However, oblique impact is commonly found in engineering practices, and, thus, relevant research is warranted. Here, the base case is subjected to the impact of the same projectile at $v=5 \mathrm{~m} / \mathrm{s}$ but with variable impact angles. The impact velocity is chosen such that it is neither too high nor too low and crack development can be well captured. Referring to Figure 16, the projectile travels vertically while the glass beam is inclined to a certain degree $\alpha$ to the vertical direction so that oblique impact is obtained and $\alpha$ is considered as the impact angle. The material properties in Table 5 are used. The typical impact fracture patterns of the glass beam at $t=1 \mathrm{~ms}$ are given in Figure 16.

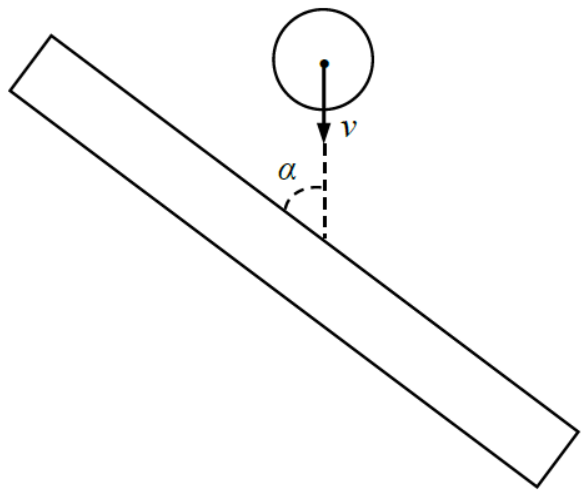

Figure 16. Definition of the impact angle $\alpha$.

According to Figure 17, should the impact angle be small, e.g., $\alpha=5^{\circ}$, just a small portion of the total impact kinetic energy is exerted onto the glass, and, hence, the damage is localized and restricted to a small region, as shown in Figure 17a. With the increase of $\alpha$, a larger portion of the total impact energy has been transferred to the glass, and the impact damage patterns change to bending cracks as the beam experiences larger flexural deformation, and considerable fragments near the impact point are found (Figure 17b,c). When $\alpha \geq 45^{\circ}$, an irregular cone-type crack is obtained within the glass body, as can be seen in Figure $17 \mathrm{~d}-\mathrm{f}$. In general, the shape of the cone is more inclined to the left of the beam, as in Figure 17e,f, and this can be explained by the distribution of the tension and the compression zones. The left upper part of the glass near the impact point is largely in tension, while the right lower part of the glass near the impact point is in compression in general, and this leads to the cone cracking more to the left, i.e., the tension zone. 


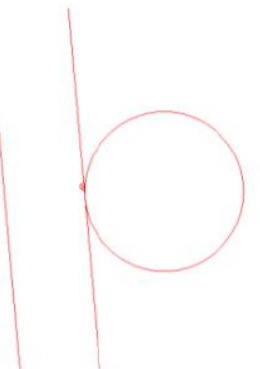

(a) $\alpha=5^{\circ}$

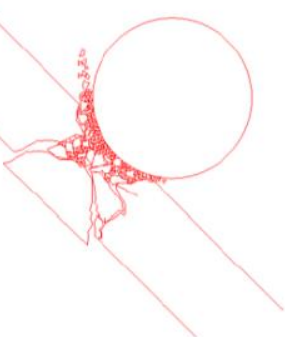

(d) $\alpha=45^{\circ}$

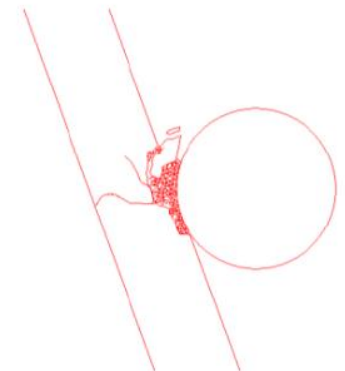

(b) $\alpha=20^{\circ}$

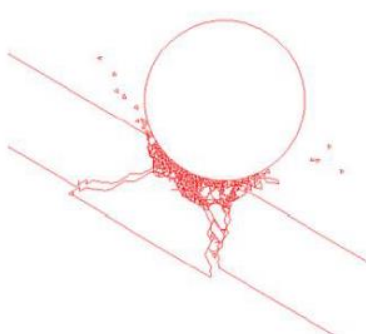

(e) $\alpha=60^{\circ}$

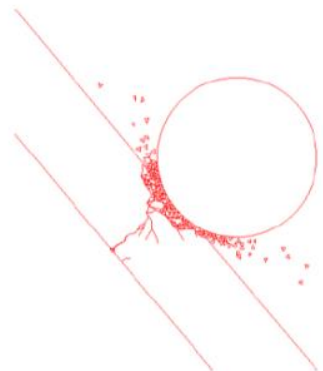

(c) $\alpha=40^{\circ}$

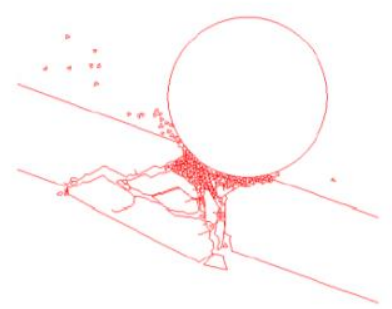

(f) $\alpha=70^{\circ}$

Figure 17. Fracture patterns of the glass beam with $v=5 \mathrm{~m} / \mathrm{s}$ and different impact angles at $t=1 \mathrm{~ms}$.

Figure 18 shows the evolution of the projectile velocity in both the horizontal and the vertical directions with different impact angles. Since the glass beam is inclined, the horizontal velocity increases with the development of time due to the bounce-back effect and the rotation of the projectile. According to Figure 18a, the highest horizontal velocity after impact is reached with $\alpha=40^{\circ}$, closing to $\alpha=45^{\circ}$ where the highest bounce-back horizontal velocity is achieved, theoretically. The horizontal velocity of the projectile is not zero even for $\alpha=90^{\circ}$ after impact, and this is largely due to the rotation of the projectile during the impact action, as the contribution from bounce-back can be neglected.

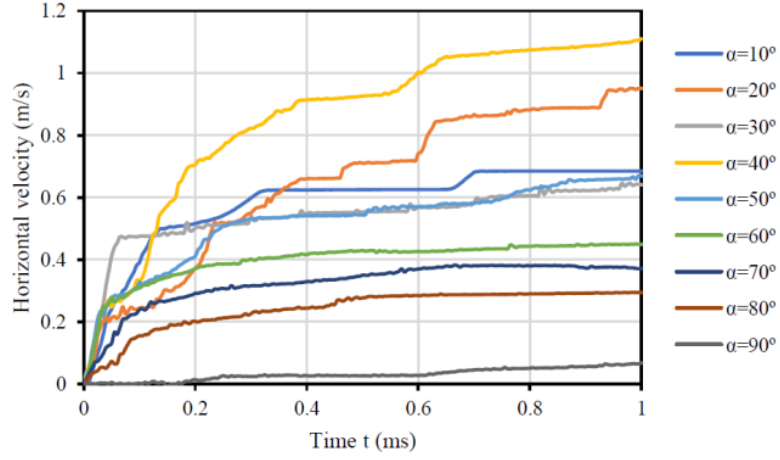

(a)

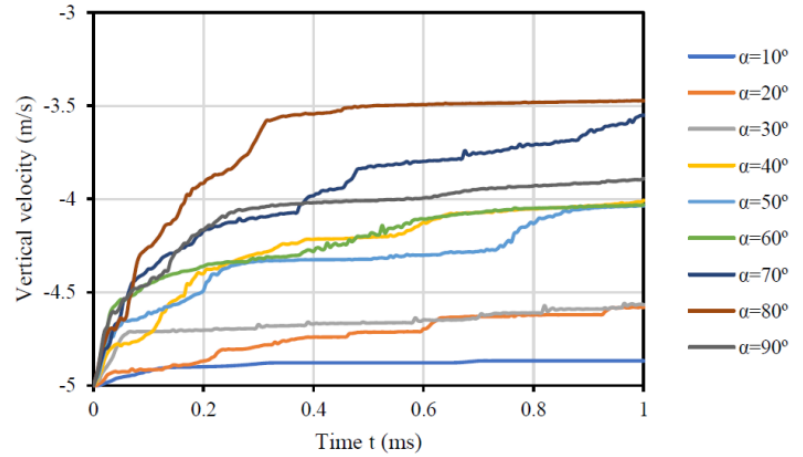

(b)

Figure 18. Evolution of the projectile velocity with different impact angles: (a) horizontal; (b) vertical.

The vertical velocity of the projectile is reduced since the impact fracture of glass consumes energy. Referring to Figure 18b, the projectile has a lower residual vertical velocity with a larger impact angle, e.g., $\alpha=70^{\circ}, 80^{\circ}$ and $90^{\circ}$, and vice versa. The residual vertical velocity of the projectile with $\alpha=90^{\circ}$ is higher than that of those with $\alpha=70^{\circ}$ and $80^{\circ}$, and this may be explained by the fact that, as the glass fractures, the projectile can move further down with $\alpha=90^{\circ}$, while it may be prevented by an inclined glass beam to some extent. The glass beam with a small impact angle has limited capacity to stop the projectile from going vertically, e.g., $\alpha=10^{\circ}, 20^{\circ}$ and $30^{\circ}$, as only $10 \%$ of the initial vertical velocity is lost during the impact by $t=1 \mathrm{~ms}$. 


\subsection{Glass Material Properties}

In this section, the influences of the glass material properties on the cracks are examined, and comparisons are made between the results of two different impact angles, $\alpha=60^{\circ}$ and $90^{\circ}$, to show the differences. The tensile strength $f_{t}$ and the fracture energy $\mathrm{G}$ are investigated, since their values determine the shape of the strain softening curve [36].

\subsubsection{Tensile Strength}

According to the previous research [36], should the fracture energy $G$ be constant, a higher tensile strength $f_{t}$ implies a higher starting point of the strain softening curve and reduces the critical separation $\delta_{c}$, and vice versa. Based on the known literature [45-48], $f_{t}$ is reasonably investigated within 20 to $200 \mathrm{MPa}$ with a $10 \mathrm{MPa}$ step. Figure 19 shows the damage patterns with $\alpha=60^{\circ}, v=5 \mathrm{~m} / \mathrm{s}$ and different $f_{t}$ at $t=1 \mathrm{~ms}$. It is observed that three different fracture patterns are captured: (i) cone cracking; (ii) half-cone cracking; (iii) flexural cracking. When $f_{t}$ is small, a Hertzian cone crack dominates, as shown in Figure 19a,b. With the increase of $f_{t}$, the impact resistance of glass increases too, and, thus, the cone cracking is no longer complete and irregular half-cone cracks are observed (Figure 19c,d). With the further increase of $f_{t}$, no cone cracking can be observed, and, instead, a through-thickness flexural crack dominates, as shown in Figure 19e,f.

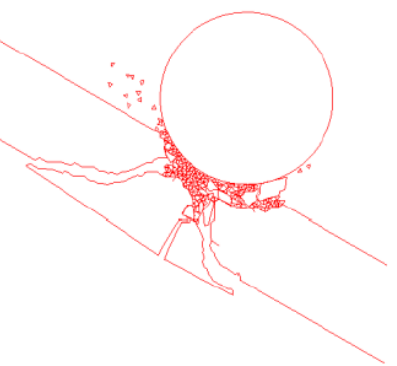

(a) $f_{t}=20 \mathrm{MPa}$

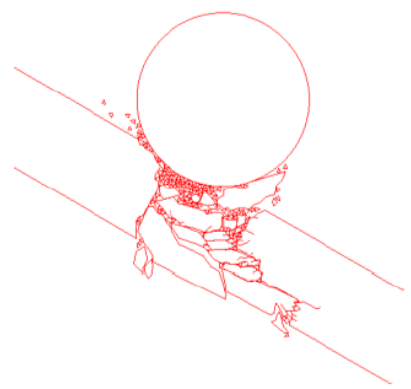

(d) $f_{t}=80 \mathrm{MPa}$

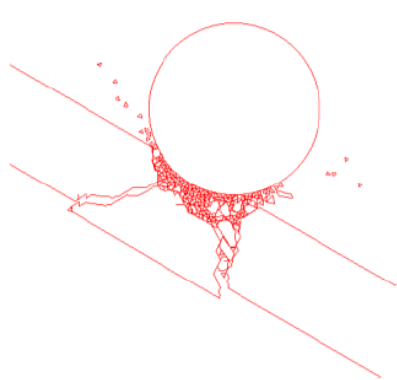

(b) $f_{t}=30 \mathrm{MPa}$

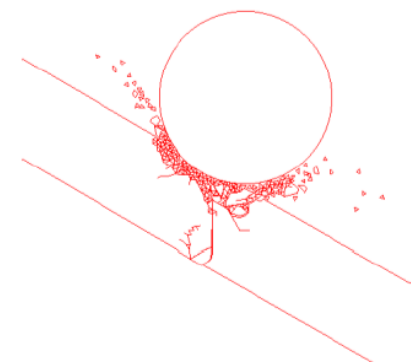

(e) $f_{t}=150 \mathrm{MPa}$

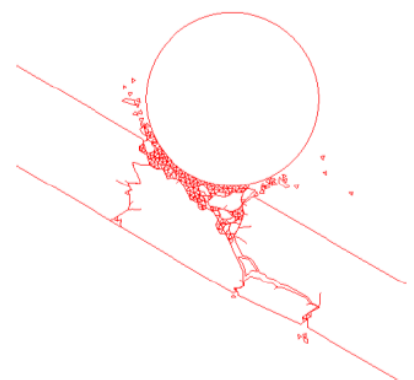

(c) $f_{t}=60 \mathrm{MPa}$

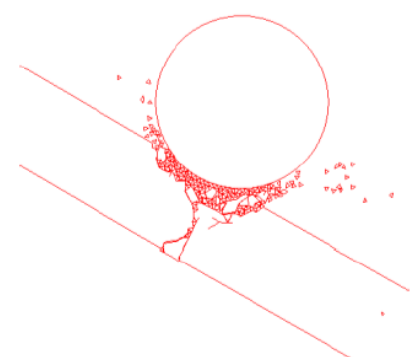

(f) $f_{t}=200 \mathrm{MPa}$

Figure 19. Fracture patterns of the glass with $\alpha=60^{\circ}, v=5 \mathrm{~m} / \mathrm{s}$ and different $f_{\mathrm{t}}$ at $t=1 \mathrm{~ms}$.

As a comparison, the fracture patterns of the same glass beam subjected to perpendicular impact are shown in Figure 20. When $f_{t} \leq 100 \mathrm{MPa}$, a cone crack can be clearly seen, as shown in Figure 20a-c. It is worth mentioning that with the increase of $f_{t}$, spalling damages around the impact point get more and more serious, as shown in Figure 20b,c, though cone cracking is still dominant. When $f_{t}>100 \mathrm{MPa}$, the impact resistance of glass is so high that no cone can be observed, and only spalling is obtained (Figure 20d-f). Based on the analyses above, the failure modes of both $60^{\circ}$ oblique impact and $90^{\circ}$ perpendicular impact are summarised in Table 7. 


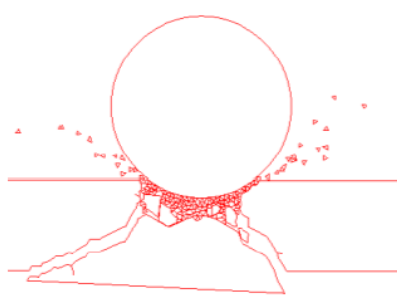

(a) $f_{t}=20 \mathrm{MPa}$

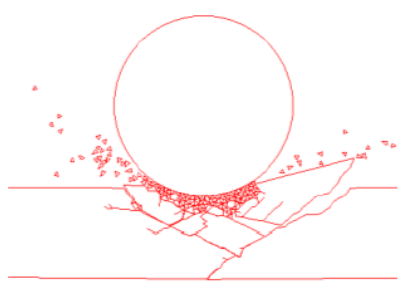

(d) $f_{t}=125 \mathrm{MPa}$

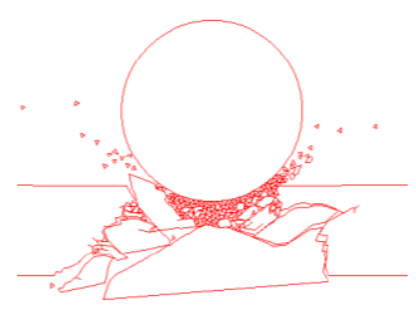

(b) $f_{t}=60 \mathrm{MPa}$

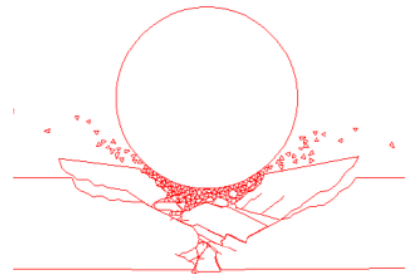

(e) $f_{t}=150 \mathrm{MPa}$

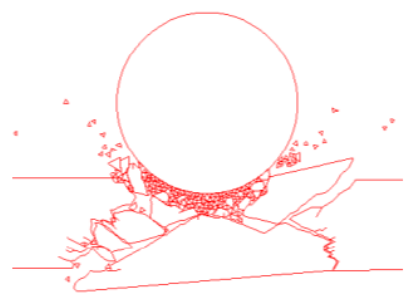

(c) $f_{t}=100 \mathrm{MPa}$

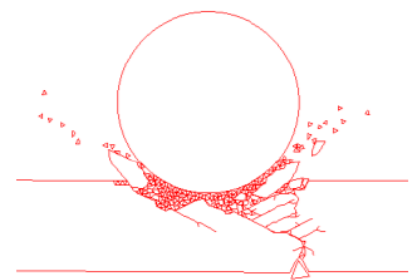

(f) $f_{t}=200 \mathrm{MPa}$

Figure 20. Fracture patterns of the glass with $\alpha=90^{\circ}, v=5 \mathrm{~m} / \mathrm{s}$ and different $f_{t}$ at $t=1 \mathrm{~ms}$.

Table 7. Impact failure modes at $v=5 \mathrm{~m} / \mathrm{s}$ with different tensile strengths of glass.

\begin{tabular}{|c|c|c|c|c|c|c|c|c|c|c|c|c|}
\hline \multirow{2}{*}{ Impact Angle } & \multicolumn{12}{|c|}{ Tensile Strength of Glass (MPa) } \\
\hline & 20 & 30 & 40 & 50 & 60 & 70 & 80 & 90 & 100 & 125 & 150 & 200 \\
\hline $60^{\circ}$ & \multicolumn{2}{|c|}{ Cone } & \multicolumn{7}{|c|}{ Half-cone } & \multicolumn{3}{|c|}{ Flexural } \\
\hline $90^{\circ}$ & \multicolumn{2}{|c|}{ Cone } & \multicolumn{7}{|c|}{ Cone + Spalling } & \multicolumn{3}{|c|}{ Spalling } \\
\hline
\end{tabular}

\subsubsection{Fracture Energy}

Should the tensile strength of glass be constant, a higher fracture energy $G$ results in a larger ultimate separation $\delta_{c}$, and, thus, the strain softening curve is flatter during the damage evolution process [36]. In this section, the fracture energy is examined in the range of 2.0 to $10.0 \mathrm{~J} / \mathrm{m}^{2}$ with a step of $1.0 \mathrm{~J} / \mathrm{m}^{2}$. Figure 21 shows the damage patterns with $\alpha=60^{\circ}, v=5 \mathrm{~m} / \mathrm{s}$ and different fracture energy $\mathrm{G}$ at $t=1 \mathrm{~ms}$. When the fracture energy is small, e.g., $\mathrm{G}=2.0 \mathrm{~J} / \mathrm{m}^{2}$, cone-shaped cracks are recognisable in general but have plenty of irregular fragments (Figure 21a). With the increase of G, typical Hertzian cone cracks are obtained, as shown in Figure $21 \mathrm{~b}-\mathrm{d}$. The further increase of $\mathrm{G}$ increases the fracture resistance of glass, and half-cone cracking is obtained when $G=9.0$ and $10.0 \mathrm{~J} / \mathrm{m}^{2}$, as shown in Figure 21e,f.

The damage patterns with $\alpha=90^{\circ}$ at $t=1 \mathrm{~ms}$ are presented in Figure 22. When $\mathrm{G}$ is small, Hertzian cone cracking dominates, as shown in Figure 22a,b. Same as the oblique impact, a half-cone cracking (Figure 22c) is obtained should the fracture energy $G$ reach some threshold, e.g., $\mathrm{G}=7.0 \mathrm{~J} / \mathrm{m}^{2}$ in this case. The cone type cracking cannot be observed any longer with a further increase of $G$, and a through-thickness flexural crack dominates when $\mathrm{G} \geq 8.0 \mathrm{~J} / \mathrm{m}^{2}$, as shown in Figure $22 \mathrm{~d}-\mathrm{f}$. The failure modes of both the oblique and perpendicular impacts are summarised in Table 8. 


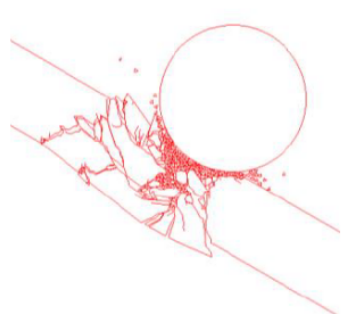

(a) $\mathrm{G}=2 \mathrm{~J} / \mathrm{m}^{2}$

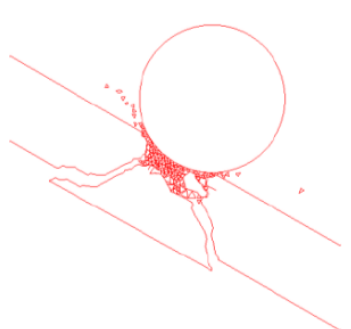

(d) $\mathrm{G}=8 \mathrm{~J} / \mathrm{m}^{2}$

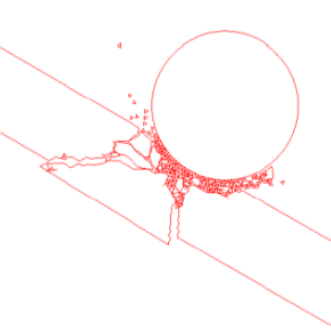

(b) $\mathrm{G}=3 \mathrm{~J} / \mathrm{m}^{2}$

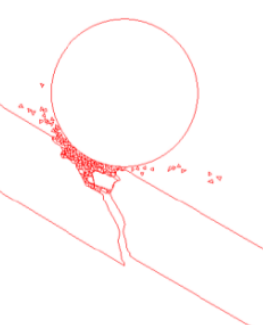

(e) $\mathrm{G}=9 \mathrm{~J} / \mathrm{m}^{2}$

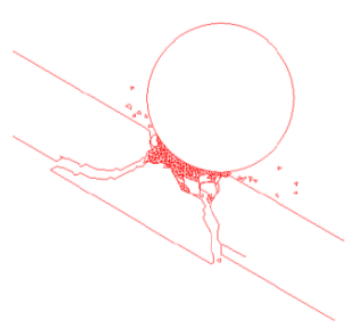

(c) $\mathrm{G}=6 \mathrm{~J} / \mathrm{m}^{2}$

Figure 21. Fracture patterns of the glass with $\alpha=60^{\circ}, v=5 \mathrm{~m} / \mathrm{s}$ and different $\mathrm{G}$ at $t=1 \mathrm{~ms}$.

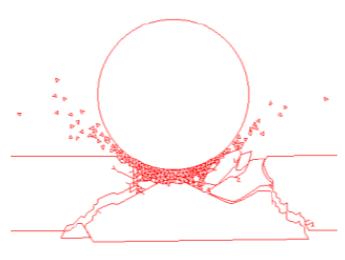

(a) $\mathrm{G}=2 \mathrm{~J} / \mathrm{m}^{2}$

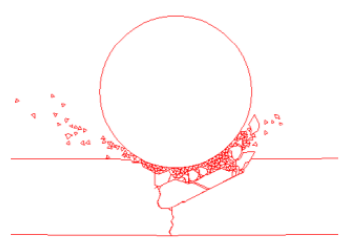

(d) $\mathrm{G}=8 \mathrm{~J} / \mathrm{m}^{2}$

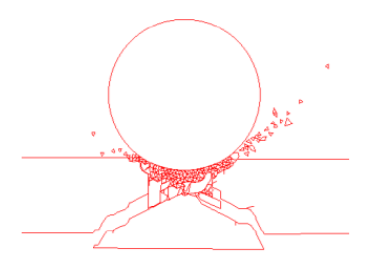

(b) $\mathrm{G}=6 \mathrm{~J} / \mathrm{m}^{2}$

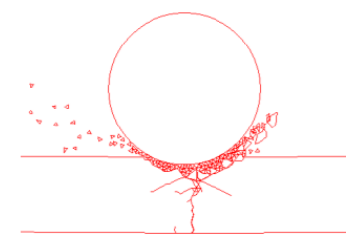

(e) $\mathrm{G}=9 \mathrm{~J} / \mathrm{m}^{2}$

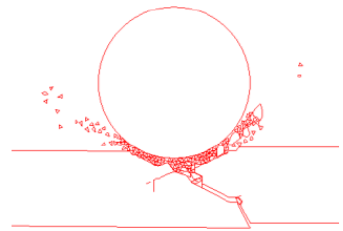

(c) $\mathrm{G}=7 \mathrm{~J} / \mathrm{m}^{2}$

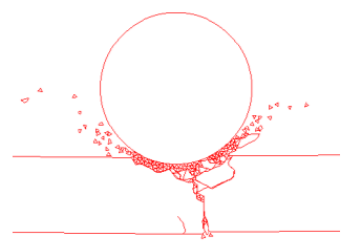

(f) $\mathrm{G}=10 \mathrm{~J} / \mathrm{m}^{2}$

Figure 22. Fracture patterns of the glass with $\alpha=90^{\circ}, v=5 \mathrm{~m} / \mathrm{s}$ and different $\mathrm{G}$ at $t=1 \mathrm{~ms}$.

Table 8. Impact failure modes at $v=5 \mathrm{~m} / \mathrm{s}$ with different fracture energies of glass.

\begin{tabular}{|c|c|c|c|c|c|c|c|c|c|}
\hline \multirow{2}{*}{ Impact Angle } & \multicolumn{9}{|c|}{ Fracture Energy of Glass $\left(\mathrm{J} / \mathrm{m}^{2}\right)$} \\
\hline & 2 & 3 & 4 & 5 & 6 & 7 & 8 & 9 & 10 \\
\hline $60^{\circ}$ & Irregular fragments & \multirow{2}{*}{\multicolumn{4}{|c|}{ Cone }} & & & \multicolumn{2}{|c|}{ Half-cone } \\
\hline $90^{\circ}$ & & & & & & Half-cone & & Flex & \\
\hline
\end{tabular}

\subsection{Threshold Velocity}

This section investigates the lowest velocity that creates a through-thickness bending crack in glass. Such a crack is commonly found in oblique or perpendicular impacts due to flexural deformation. Based on the FDEM simulations, Figure 23 plots the threshold velocity against the impact angle $\alpha$. It is observed that the threshold velocity is descending with three phases: (i) from $\alpha=5^{\circ}$ to $\alpha=10^{\circ}$; (ii) from $\alpha=10^{\circ}$ to $\alpha=35^{\circ}$; (iii) from $\alpha=35^{\circ}$ 
to $\alpha=90^{\circ}$. When $\alpha$ is small, e.g., $\alpha=5^{\circ}$, a much higher impact velocity $(v=15.5 \mathrm{~m} / \mathrm{s})$ is required to form a bending crack, as only a very small portion of the impact energy can be utilised for the deformation and fracture of glass. With the increase of the impact angle, the threshold velocity decreases remarkably to $v=5 \mathrm{~m} / \mathrm{s}$ when $\alpha=10^{\circ}$. The curve descends in a much flatter slope to $v=2 \mathrm{~m} / \mathrm{s}$ when $\alpha=35^{\circ}$. Afterwards, the curve descends further in an even flatter slope and fluctuates within a narrow band.

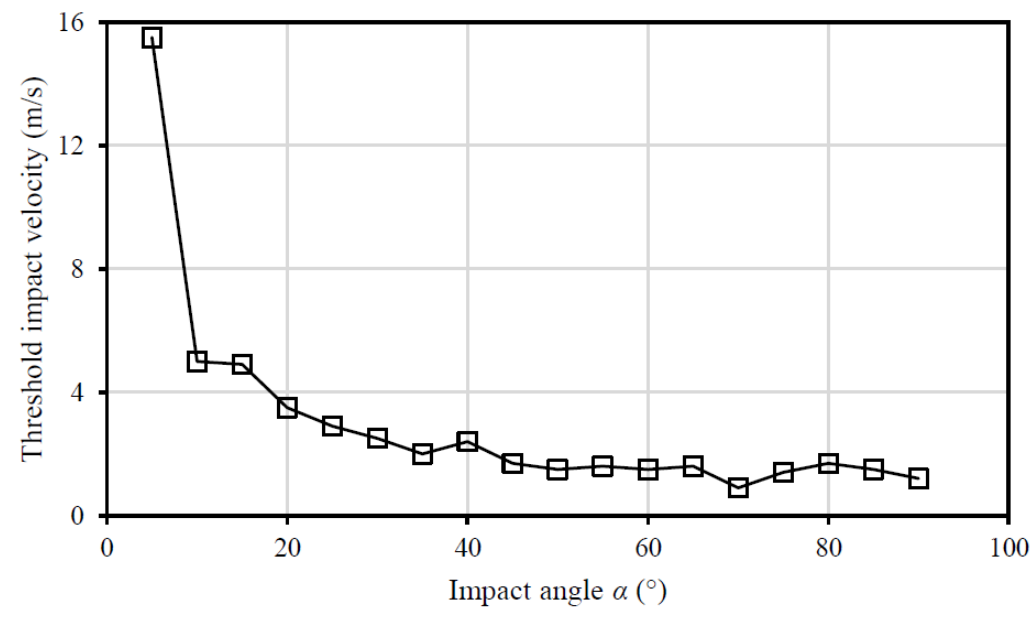

Figure 23. The threshold impact velocity for creating through-thickness bending cracks.

\section{Concluding Remarks}

The FDEM has been used in this paper for parametric investigation of both the oblique and perpendicular impact fracture of glass. The basic theories of the FDEM and the cohesive fracture model of glass were briefly introduced. Numerical examples were shown for verification purposes.

A convergence study on the impact responses with different meshes was performed in Section 5.1, demonstrating the reliability and robustness of the FDEM in simulating the impact fracture of glass. In Section 5.2, four different types of damage, namely the local minor, bending, cone and punching failure, were captured when the impact velocity varied. The correlations between the impact velocity and the impact failure modes were revealed. The obtained data points agree with the established breakage regimes [36] very well. The influence of the impact angle was examined in Section 5.3, and it was concluded that the damage becomes more and more serious with the increase of the impact angle. Glass material properties like the tensile strength and fracture energy play parts in the impact failure responses, and their influences were studied in Section 5.4. Different failure modes such as cone, half-cone, bending, spalling, etc. were obtained, and their relevance to glass material properties were summarised in Tables 7 and 8 . The threshold velocity for creating a dominant through-thickness bending crack against impact angles is investigated in Section 5.5. The obtained threshold velocity curve is in a clear descending trend, and it fluctuates within a narrow band after $\alpha=35^{\circ}$.

Based on the parametric investigation in this study, guidance can be suggested for the design and manufacturing of glass, and comparative benchmark examples for both the oblique and the perpendicular impacts are also provided for future research.

Author Contributions: Conceptualization, X.C. (Xudong Chen); methodology, X.C. (Xudong Chen) and A.C.; software, X.C. (Xudong Chen); validation, X.C. (Xiangxiang Chen) and X.C. (Xudong Chen); formal analysis, X.C. (Xiangxiang Chen), Y.C. and H.W.; writing-original draft preparation, X.C. (Xiangxiang Chen) and X.C. (Xudong Chen); writing-review and editing, X.C. (Xudong Chen), X.C. (Xiangxiang Chen), A.C., Y.C. and H.W.; supervision, X.C. (Xudong Chen) and A.C.; project administration, X.C. (Xudong Chen); funding acquisition, X.C. (Xudong Chen) and X.C. (Xiangxiang Chen). All authors have read and agreed to the published version of the manuscript. 
Funding: This research was funded by the National Natural Science Foundation of China (No. 51808368), the Qinglan Project of Jiangsu Province of China, and the Postgraduate Research \& Practice Innovation Program of Jiangsu Province (SJCX20_1096).

Data Availability Statement: Not applicable.

Acknowledgments: The support for the FDEM program ' $Y$ ' from A. Munjiza is highly appreciated.

Conflicts of Interest: The authors declare no conflict of interest.

\section{References}

1. Martin, J.W. Materials for Engineering; Woodhead Publishing: Sawston, UK, 2006.

2. Masters, F.J.; Gurley, K.R.; Shah, N.; George, F. The vulnerability of residential window glass to lightweight windborne debris. Eng. Struct. 2010, 32, 911-921. [CrossRef]

3. Preston, F.W. A study of the rupture of glass. J. Soc. Glass Technol. 1926, 10, 234-269.

4. Shand, E.B. Experimental study of the fracture of glass. I. The fracture process. J. Am. Ceram. Soc. 1954, 37, 52-59. [CrossRef]

5. $\quad$ Baird, K.M. Shock wave in glass. Nature 1947, 160, 24-25. [CrossRef]

6. $\mathrm{Hu}, \mathrm{W} . ;$ Wang, Y.; Yu, J.; Yen, C.F.; Bobaru, F. Impact damage on a thin glass plate with a thin polycarbonate backing. Int. J. Impact Eng. 2013, 62, 152-165. [CrossRef]

7. Kozłowski, M. Experimental and numerical assessment of structural behaviour of glass balustrade subjected to soft body impact. Compos. Struct. 2019, 229, 111380. [CrossRef]

8. Repetto, E.A.; Radovitzky, R.; Ortiz, M. Finite element simulation of dynamic fracture and fragmentation of glass rods. Comput. Methods Appl. Mech. Eng. 2000, 183, 3-14. [CrossRef]

9. Sun, X.; Khaleel, M.A.; Davies, R.W. Modeling of stone-impact resistance of monolithic glass ply using continuum damage mechanics. Int. J. Damage Mech. 2005, 14, 165-178. [CrossRef]

10. Grujicic, M.; Pandurangan, B.; Coutris, N.; Cheeseman, B.A.; Fountzoulas, C.; Patel, P.; Templeton, D.W.; Bishnoi, K.D. A simple ballistic material model for soda-lime glass. Int. J. Impact Eng. 2009, 36, 386-401. [CrossRef]

11. Mohagheghian, I.; Wang, Y.; Jiang, L.; Zhang, X.; Guo, X.; Yan, Y.; Kinloch, A.J.; Dear, J.P. Quasi-static bending and low velocity impact performance of monolithic and laminated glass windows employing chemically strengthened glass. Eur. J. Mech. A/Solids 2017, 63, 165-186. [CrossRef]

12. Kozłowski, M.; Zemła, K.; Kosmal, M. Exploratory finite element analysis of monolithic toughened glass panes subjected to hard-body impact. IOP Conf. Ser. Mater. Sci. Eng. 2021, 1203, 022145. [CrossRef]

13. Kozłowski, M.; Zemła, K.; Kosmal, M.; Kopyłow, O. Experimental and FE Study on Impact Strength of Toughened GlassRetrospective Approach. Materials 2021, 14, 7658. [CrossRef] [PubMed]

14. Zang, M.Y.; Lei, Z.; Wang, S.F. Investigation of impact fracture behavior of automobile laminated glass by 3D discrete element method. Comput. Mech. 2007, 41, 73-83. [CrossRef]

15. Xu, W.; Zang, M.; Gao, W. Adaptive combined DE/FE algorithm for brittle fracture of plane stress problems. Comput. Mech. 2014, 54, 535-546. [CrossRef]

16. Baraldi, D.; Cecchi, A.; Foraboschi, P. Broken tempered laminated glass: Non-linear discrete element modelling. Compos. Struct. 2016, 140, 278-295. [CrossRef]

17. Gao, W.; Liu, X.; Chen, S.; Bui, T.Q.; Yoshimura, S. A cohesive zone based DE/FE coupling approach for interfacial debonding analysis of laminated glass. Theor. Appl. Fract. Mech. 2020, 108, 102668. [CrossRef]

18. Ghaffari, D.; Ahmadi, S.R.; Shabani, F. XFEM simulation of a quenched cracked glass plate with moving convective boundaries. Comptes Rendus Mec. 2016, 344, 78-94. [CrossRef]

19. Wu, L.; Wang, L.; Huang, D.; Xu, Y. An ordinary state-based peridynamic modeling for dynamic fracture of laminated glass under low-velocity impact. Compos. Struct. 2020, 234, 111722. [CrossRef]

20. Ha, Y.D. An extended ghost interlayer model in peridynamic theory for high-velocity impact fracture of laminated glass structures. Comput. Math. Appl. 2020, 80, 744-761. [CrossRef]

21. Munjiza, A. The Combined Finite-Discrete Element Method; John Wiley and Sons: Hoboken, NJ, USA, 2004.

22. Munjiza, A. Discrete Elements in Transient Dynamics of Fractured Media. Ph.D. Thesis, Department of Civil Engineering, University of Wales, Swansea, UK, 1992.

23. Munjiza, A.; Andrews, K.R.F. NBS contact detection algorithm for bodies of similar size. Int. J. Numer. Methods Eng. 1998, 43, 131-149. [CrossRef]

24. Munjiza, A.; Andrews, K.R.F.; White, J.K. Combined single and smeared crack model in combined finite-discrete element analysis. Int. J. Numer. Methods Eng. 1999, 44, 41-57. [CrossRef]

25. Williams, J.R. Contact analysis of large numbers of interacting bodies using discrete modal methods for simulating material failure on the microscopic scale. Eng. Comput. 1988, 3, 197-209. [CrossRef]

26. Munjiza, A.; John, N.W.M. Mesh size sensitivity of the combined FEM/DEM fracture and fragmentation algorithms. Eng. Fract. Mech. 2002, 69, 281-295. [CrossRef]

27. Munjiza, A.; Knight, E.E.; Rougier, E. Computational Mechanics of Discontinua; John Wiley and Sons: Hoboken, NJ, USA, 2011 
28. Munjiza, A.; Rougier, E.; Knight, E.E. Large Strain Finite Element Method: A Practical Course; John Wiley and Sons: Hoboken, NJ, USA, 2015.

29. Chen, X.; Wang, H. Slope failure of noncohesive media modelled with the combined finite-discrete element method. Appl. Sci. 2019, 9, 579. [CrossRef]

30. Chen, X.; Wang, H.; Chan, A.H.C.; Agrawal, A.K. Dynamic failure of dry-joint masonry arch structures modelled with the combined finite-discrete element method. Comput. Part. Mech. 2020, 7, 1017-1028. [CrossRef]

31. Chen, X.; Wang, H.; Chan, A.H.C.; Agrawal, A.K.; Cheng, Y. Collapse simulation of masonry arches induced by spreading supports with the combined finite-discrete element method. Comput. Part. Mech. 2021, 8, 721-735. [CrossRef]

32. Chen, X.; Wang, X.; Wang, H.; Agrawal, A.K.; Chan, A.H.C.; Cheng, Y. Simulating the failure of masonry walls subjected to support settlement with the combined finite-discrete element method. J. Build. Eng. 2021, 43, 102558. [CrossRef]

33. Li, W.; Chen, X.; Wang, H.; Chan, A.H.C.; Cheng, Y. Evaluating the seismic capacity of masonry arch structures via the combined finite-discrete element method. Appl. Sci. 2021, 11, 8725. [CrossRef]

34. Chen, X. Investigation on the Impact Damage of Glass Using the Combined Finite/Discrete Element Method. Ph.D. Thesis, School of Civil Engineering, University of Birmingham, Birmingham, UK, 2013.

35. Chen, X.D.; Chan, A.H.C.; Yang, J. FEM/DEM modelling of hard body impact on the laminated glass. Appl. Mech. Mater. 2014, 553, 786-791. [CrossRef]

36. Chen, X.; Chan, A.H.C.; Yang, J. Simulating the breakage of glass under hard body impact using the combined finite-discrete element method. Comput. Struct. 2016, 177, 56-68. [CrossRef]

37. Chen, X.; Chan, A.H.C. Modelling impact fracture and fragmentation of laminated glass using the combined finite-discrete element method. Int. J. Impact Eng. 2018, 112, 15-29. [CrossRef]

38. Chen, X.; Chan, A.H.C. Soft impact responses of laminated glass simulated with the combined finite-discrete element method. Eng. Comput. 2018, 35, 1460-1480. [CrossRef]

39. Munjiza, A.; Lei, Z.; Divic, V.; Peros, B. Fracture and fragmentation of thin shells using the combined finite-discrete element method. Int. J. Numer. Methods Eng. 2013, 95, 478-498. [CrossRef]

40. Lei, Z.; Rougier, E.; Knight, E.E.; Zang, M.; Munjiza, A. Impact fracture and fragmentation of glass via the 3D combined finite-discrete element method. Appl. Sci. 2021, 11, 2484. [CrossRef]

41. Anderson, T.L. Fracture Mechanics: Fundamentals and Applications; CRC Press: Boca Raton, FL, USA, 1991.

42. Hillerborg, A.; Modéer, M.; Petersson, P.E. Analysis of crack formation and crack growth in concrete by means of fracture mechanics and finite elements. Cem. Concr. Res. 1976, 6, 773-781. [CrossRef]

43. Ha, Y.D. Dynamic fracture analysis for 2D multilayered glass structures considering interlayer effects. J. Mech. Sci. Technol. 2019, 33, 3641-3648. [CrossRef]

44. Xu, W.; Zang, M. Four-point combined DE/FE algorithm for brittle fracture analysis of laminated glass. Int. J. Solids Struct. 2014, 51, 1890-1900. [CrossRef]

45. Poleshko, A.P.; Goralik, E.T. Tensile strength of technical ceramics and glass. Strength Mater. 1981, 13, 344-347. [CrossRef]

46. Ledbetter, L.R.; Walker, A.R.; Keiller, A.P. Structural use of glass. J. Archit. Eng. 2006, 12, 137-149. [CrossRef]

47. Sedlacek, G.; Blank, K.; Gusgen, J. Glass in structural engineering. Struct. Eng. 1995, 73, 17-22.

48. Overend, M.; Zammit, K. A computer algorithm for determining the tensile strength of float glass. Eng. Struct. 2012, 45, 68-77. [CrossRef]

49. Holloway, D.G. The fracture of glass. Phys. Educ. 1968, 3, 317-322. [CrossRef]

50. Linger, K.R.; Holloway, D.G. The fracture energy of glass. Philos. Mag. 1968, 18, 1269-1280. [CrossRef]

51. Michio, I.; Kazuhiro, U.; Shinsuke, T.; Yasuo, G.; Mototsugu, S. Work of fracture and crack healing in glass. J. Am. Ceram. Soc. 2006, 68, 704-706. 